\title{
Research Paper \\ Prediction of Suicide Ideation Based on the Attentional Bias in Clinical and Non-clinical Populations
}

\author{
Elham Baghani ${ }^{1}\left(\mathbb{D},{ }^{*}\right.$ Ladan Fata $^{1,2}\left(\mathbb{D}\right.$, Mahdiyeh Salehi $^{1}$, Fariba Hasani ${ }^{1}$
}

1. Department of General Psychology, Central Tehran Branch, Islamic Azad University, Tehran, Iran. 2. Iran University of Medical Sciences, Tehran, Iran.

\begin{tabular}{|c|c|}
\hline $\begin{array}{l}\text { Use your device to scan } \\
\text { and read the article online }\end{array}$ & Chtation Baghani E, Fata L, Salehi M, Hasani F. [Prediction of Suicide Ideation Based on the Attentional Bias in Clinical and \\
\hline 口itinitiv & $\begin{array}{l}\text { Non-clinical Populations (Persian)]. Iranian Journal of Psychiatry and Clinical Psychology. 2020; 26(1):76-101. http://dx.doi. } \\
\text { org/10.32598/ijpcp.26.1.3170.1 }\end{array}$ \\
\hline 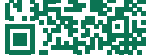 & doi'http://dx.doi.org/10.32598/ijpcp.26.1.3170.1 \\
\hline
\end{tabular}

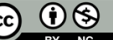

Received: 11 Aug 2019 Accepted: 11 Dec 2019 Available Online: $01 \mathrm{Apr} 2020$

Key words: Stroop test, Attentional bias, Suicide, Suicide ideation, Suicide attempt

\section{ABSTRACT}

Objectives This study aimed to predict the suicide ideation based on the attentional bias in clinical and non-clinical populations.

Methods Participants were 120 individuals (77 women and 43 men, age range 18-40 years) who were purposively selected and divided into three groups of clinical-suicidal $(n=40)$, clinical non-suicidal $(n=40)$ and non-clinical ( $n=40$ ). They were measured by Suicide Stroop Test and Beck Scale for Suicide Ideation (BSS). Three indices of attentional bias including reaction time, time interference and interference ratio were calculated and the data were analyzed using paired-samples t-test, Pearson correlation coefficient and multivariate regression analysis at the $95 \%$ confidence level.

Results There was no significant difference in the mean reaction time means between all types of Stroop test (positive emotional, negative emotional, and suicide) in comparison with the neutral Stroop $(\mathrm{P}<0.05)$. Suicide ideation was significantly correlated with the overall reaction time in the positive emotional Stroop ( $r=0.32, P<0.001)$, negative emotional Stroop $(r=0.27, P<0.01)$, suicide Stroop ( $r=0.28$, $P<0.01)$ and with the interference time of the non-clinical group in the suicide Stroop $(r=0.33, P<0.05)$. In other cases, the relationships between variables were not statistically significant $(P>0.05)$. Regression analysis based on the overall mean scores showed that age $(\beta=-0.225)$, gender $(\beta=0.223)$, clinical conditions $(\beta=0.224)$ and recent suicide attempt $(\beta=0.424)$ explaining $44 \%$ of the variances, were significant predcitors of suicide ideation, while the attentional bias indices failed to play any significant role in predicting suicide ideation ( $P>0.05)$.

Conclusion It seems that the incidence of attentional bias towards suicide-related information is not related to clinical conditions, and the relationship between attentional bias and suicide ideation does not follow a certain pattern. Factors such as age, gender, clinical status, and past suicidal behaviors are important predictors of suicide ideation, but attentional bias indicators cannot predict suicide ideation.

\section{Extended Abstract}

\section{Introduction}

uicide is a global phenomenon and occurs throughout the lifespan. Close to 800 thousand people die due to suicide every year which is one person every 40 seconds. There are indications that for each adult who died by suicide there may have been more than 20 others attempting suicide [1]. It is, therefore, critical to identify the factors that influence suicidal behavior. This study aimed to predict suicide

a

* Corresponding Author:

Ladan Fata, PhD.

Address: Department of General Psychology, Central Tehran Branch, Islamic Azad University, Tehran, Iran.

Tel: +98 (21) 22481632

E-mail: Ifata@yahoo.com 
ideation based on the attentional bias in clinical and non-clinical populations.

\section{Methods}

Participants were 120 individuals (77 women and 43 men) aged 18-40 years who were purposively selected from among suicide attempters and psychiatric outpatients referred to hospitals and medical centers in Tehran as well as non-clinical subjects divided into three groups of clinical-suicidal $(n=40)$, clinical nonsuicidal $(n=40)$ and non-clinical $(n=40)$. The criteria for entering study for non-clinical group was having the General Health Questionnaire score of less than 23 [30]. Suicide Stroop Test was used to measure attentional bias in response to positive emotional, negative emotional and suicide-related stimuli, and Beck Scale for Suicide Ideation $[37,38]$ was used to measure the suicidal thoughts. Three indices of attentional bias including reaction time, time interference and interference ratio were calculated and the data were analyzed using paired-samples t-test, Pearson correlation coefficient and multivariate regression analysis at the $95 \%$ confidence level.

Table 1. The result of multiple regression models by group and scoring method

\begin{tabular}{|c|c|c|c|c|c|c|c|c|}
\hline \multirow{2}{*}{ Predictive Variable } & \multicolumn{4}{|c|}{ Suicidal Clinical (n=40) } & \multicolumn{4}{|c|}{ Non-suicidal Clinical ( $n=40)$} \\
\hline & $\boldsymbol{\beta}$ & $\mathbf{R}$ & $\mathbf{R 2}$ & $\mathbf{F}$ & $\boldsymbol{\beta}$ & $\mathbf{R}$ & $\mathbf{R 2}$ & $\mathbf{F}$ \\
\hline Reaction time & & 0.171 & 0.029 & 0.263 & & 0.301 & 0.090 & 0.870 \\
\hline neutral stroop & -0.056 & & & & 0.139 & & & \\
\hline positive stroop & 0.179 & & & & -1.01 & & & \\
\hline negative stroop & 0.279 & & & & 0.205 & & & \\
\hline suicide stroop & -0.296 & & & & 0.596 & & & \\
\hline Interference time & & 0.103 & 0.011 & 0.127 & & 0.107 & 0.011 & 0.138 \\
\hline positive stroop & 0.038 & & & & -0.282 & & & \\
\hline negative stroop & 0.106 & & & & 0.130 & & & \\
\hline suicide stroop & -0.110 & & & & 0.106 & & & \\
\hline Interference Ratio & & 0.090 & 0.008 & 0.098 & & 0.126 & 0.016 & 0.195 \\
\hline positive stroop & 0.012 & & & & -0.134 & & & \\
\hline negative stroop & -0.102 & & & & 0.003 & & & \\
\hline suicide stroop & -0.107 & & & & 0.197 & & & \\
\hline \multirow{2}{*}{ Predictive Variable } & \multicolumn{4}{|c|}{ Non-clinical $(n=40)$} & \multicolumn{4}{|c|}{ Total Sample $(n=40)$} \\
\hline & $\boldsymbol{\beta}$ & $\mathbf{R}$ & $\mathbf{R 2}$ & $\mathbf{F}$ & $\boldsymbol{\beta}$ & $\mathbf{R}$ & $\mathbf{R 2}$ & $\mathbf{F}$ \\
\hline Reaction time & & 0.355 & 0.126 & 1.26 & & 0.320 & 0.103 & $* 3.29$ \\
\hline neutral stroop & -0.319 & & & & -0.026 & & & \\
\hline positive stroop & -0.039 & & & & $* 0.353$ & & & \\
\hline negative stroop & -0.127 & & & & -0.08 & & & \\
\hline suicide stroop & 0.495 & & & & 0.065 & & & \\
\hline Interference time & & 0.344 & 0.118 & $* 3.42$ & & 0.10 & 0.01 & 0.391 \\
\hline positive stroop & -0.042 & & & & 0.021 & & & \\
\hline negative stroop & -0.104 & & & & -0.149 & & & \\
\hline suicide stroop & $* 0.392$ & & & & 0.161 & & & \\
\hline Interference Ratio & & 0.304 & 0.903 & 1.22 & & 0.11 & 0.012 & 0.473 \\
\hline positive stroop & -0.017 & & & & 0.047 & & & \\
\hline negative stroop & -0.114 & & & & -0.101 & & & \\
\hline suicide stroop & 0.340 & & & & 0.119 & & & \\
\hline
\end{tabular}

Iranian Journal of 


\section{Results}

The longest reaction time and the highest time interference for suicide-related words were observed in the clinical-suicidal group ( $32.887 \pm 130.76 \mathrm{~ms})$. Regardless of the group type, the fastest and slowest reaction times were related to the positive emotional Stroop ( $-24.325 \pm 151.12 \mathrm{~ms})$ and suicide Stroop $(11.58 \pm 160.30 \mathrm{~ms})$, respectively. Paired t-test results showed no significant difference in mean reaction time between all types of Stroop tests (positive emotional, negative emotional, and suicide) in comparison to the neutral Stroop $(\mathrm{P}<0.05)$. However, at $90 \%$ confidence level, the mean reaction time for the positive emotional Stroop in the non-suicidal clinical group $(\Delta M=59.30$ $\mathrm{ms}, \mathrm{t}=-1.71, \mathrm{P}=0.09)$ and the overall reaction time $(\Delta \mathrm{M}=24.32 \mathrm{~ms}, \mathrm{t}=-1.76, \mathrm{P}=0.08)$ were faster than those of the neutral Stroop.

Pearson correlation coefficient revealed that suicide ideation was significantly correlated with the overall reaction time in the positive emotional Stroop $(r=0.32$, $\mathrm{P}<0.001)$, negative emotional Stroop $(\mathrm{r}=0.27, \mathrm{P}<0.01)$, suicide Stroop $(\mathrm{r}=0.28, \mathrm{P}<0.01)$ and with the interference time of the non-clinical group in the suicide Stroop $(r=0.33, P<0.05)$. In other cases, the relationships between variables were not statistically significant $(\mathrm{P}>0.05)$. Regression analysis results showed that gender explaining $25 \%$ of the variance, was the only significant determinant of suicide ideation in the clinical-suicidal group $(\beta=0.434)$. In the clinical nonsuicidal group, although attentional bias explained 6 to $7 \%$ of the variance, age accounting for $34 \%$ of the variance was the only significant determinant of suicide ideation $(\beta=-0.324)$.

Moreover, $11.8 \%$ of the variance in suicide ideation of the non-clinical group was explained by attentional bias in the suicide Stroop ( $\beta=0.392)$, but no other variables had a significant role in explaining changes in suicide ideation after controlling for the role of demographic and general health variables in the non-clinical group $(P>0.05)$. In overall, age $(\beta=-0.225)$, gender $(\beta=0.223)$, clinical conditions $(\beta=0.224)$ and recent suicide attempt ( $\beta=0.424$ ) explaining $44 \%$ of the variances, were significant determinants of suicide ideation and attentional bias indices failed to play any significant role in predicting suicide ideation $(\mathrm{P}>0.05)$ (Table 1$)$.

\section{Discussion}

The clinical and non-clinical population investigated in this study did not show significant attentional bias in the suicide Stroop; hence, it seems that the incidence of attentional bias towards suicide-related information is not related to clinical conditions. Chung and Jaglic (2016), Richard-Devantoy et al. (2016) and Wilson et al. (2019), reported no significant difference between the reaction times of neutral, positive emotional, negative emotional, and suicide Stroop tests [9-11] which is consistent with the findings of the present study. However, Becker et al. (1999) and William and Bordbent (1986) reported that the reaction time of suicide Stroop in suicide attempters was significantly longer than that of other types of Stroop tests [12, 13].

According to the present study, age, gender, clinical status, and past suicidal behaviors were significant predictors of suicide ideation, but the indices of attentional bias towards suicide-related information could not predict suicide ideation. Most of the studies in literature have studied the predictive power of attentional bias in relation to suicide attempt, but regarding the suicide ideation, only a simple relationship between attentional bias and suicide ideation has been reported. Most of these studies have shown that there is no significant correlation between attentional bias in suicide strop and suicide ideation [9, 10], but in other stuides, a weak to moderate correlation between attentional bias and suicide ideation has been reported [12].

According to the cognitive model of suicidal behavior, suicide schema directs the biased mechanism of attention to suicidal-related cues and the inability to disengage from suicide-related cues, resulting in attention fixation on suicide-related information. Throughout this process, state hopelessness as a maladaptive cognitive content that reflects one's conclusion of the intolerable and unchanging status quo, is involved in the biased processing of suicide-related information and fixation of attention. These conditions finally contribute to the formation of suicide ideation. Based on the findings, it can be concluded that the relationship between attentional bias towards suicide-related information and suicide ideation does not follow a certain pattern, and it may be due to the role of mediating variables in their relationship which should be addressed in future studies.

\section{Ethical Considerations}

\section{Compliance with ethical guidelines}

All ethical principles were considered in this study. The participants were informed about the study objectives and methods, and signed a written consent form; 
they were also assured of the confidentiality of their information; Moreover, they were allowed to leave the study at any time, and if desired, the results of the research would be available to them.

\section{Funding}

This study did not receive any specific grant from funding agencies in the public, commercial, or nonprofit sectors.

\section{Authors contributions}

All authors contributed in preparing this article.

\section{Conflicts of interest}

The authors declared no conflict of interest. 
This Page Intentionally Left Blank 


\title{
يبشبينى تفكر خودكشى بر اساس سوتيرى توجه در جمعيت بالينى وغيربالينى
}

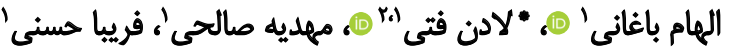 \\ ا. كروه روانشناسى عمومى، واحد تّهران مركزي، دانشكاه آزاد اسلامي، تيهران، ايران. \\ r. أشُكاه علوم يزشكى ايران، تهران، ايران.
}

\begin{abstract}
حكبد

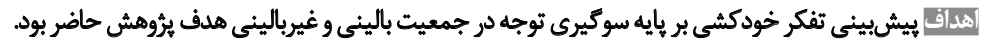

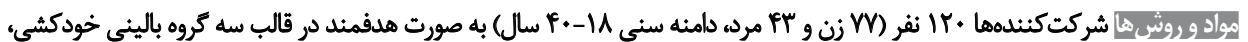

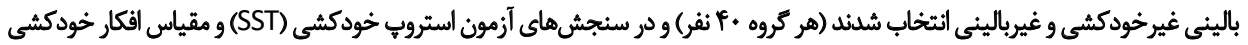

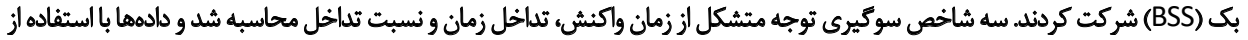

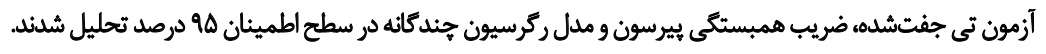

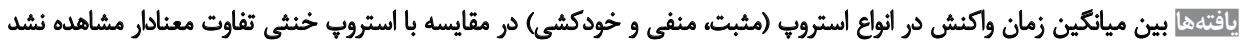

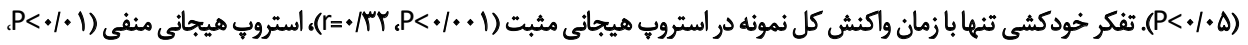

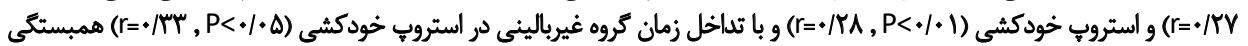

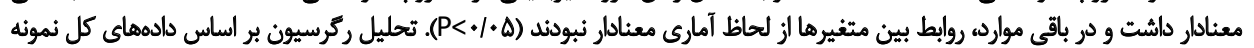

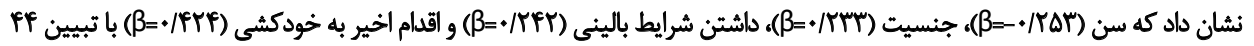

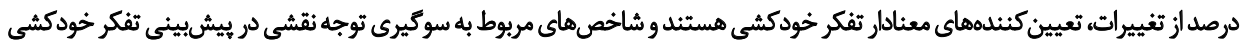

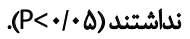

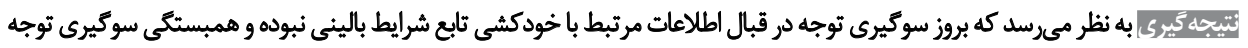

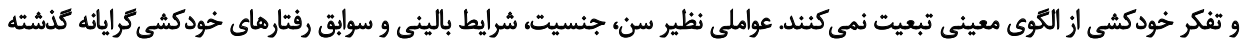

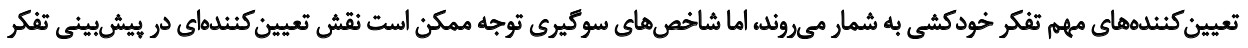

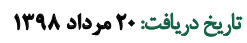

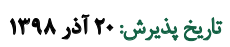

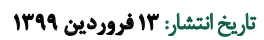

خودكشى در سراسر طول عمر وجود دارد، اما در سال 19 • ب بين

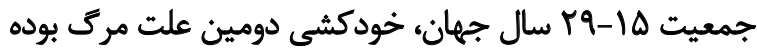

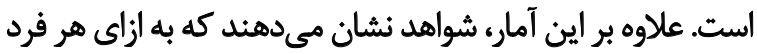

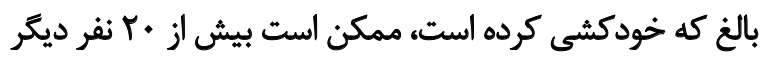
[قدام به خودكشى كرده باشند [1 [1]

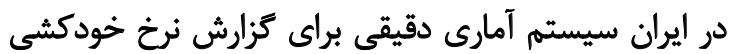

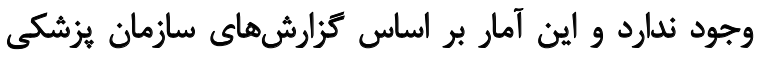

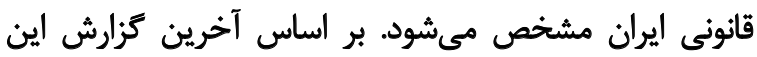

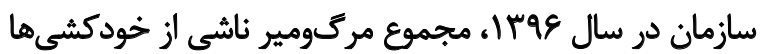

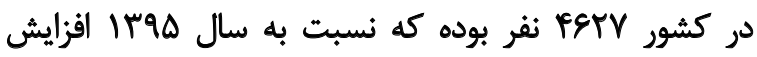

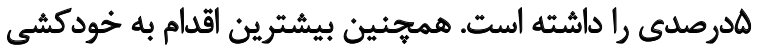

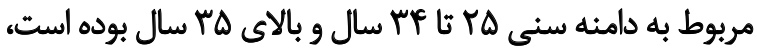

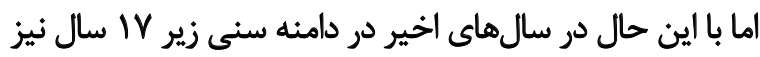

مقلمه

أمروزه خودكشى 'يك يديده و جالش جهانى محسوب مى آشود.

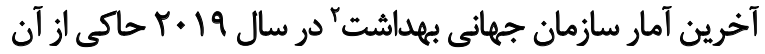

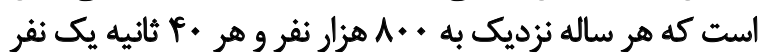

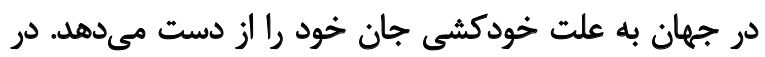

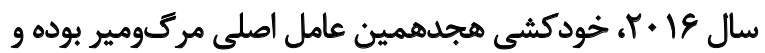

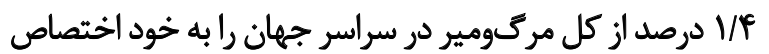

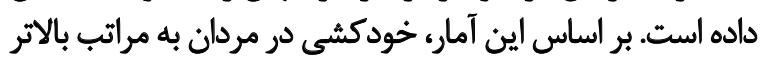

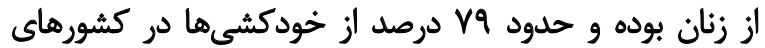

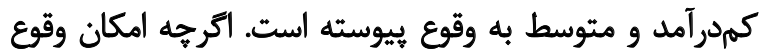

\section{Suicide}

2. World Health Organization (WHO)

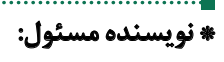$$
\text { دكثر لادن فتي }
$$

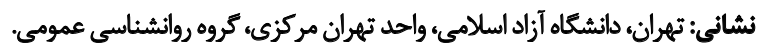
تلفن: Ifata@yahoo.com: بيست الكترونيكي 


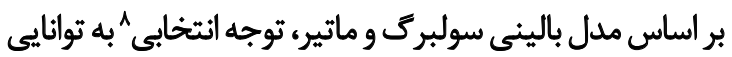

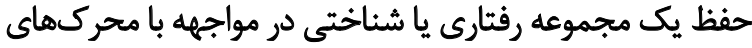

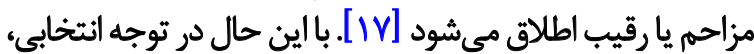

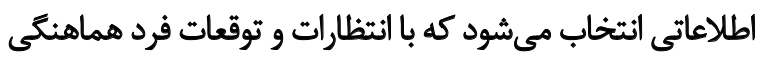

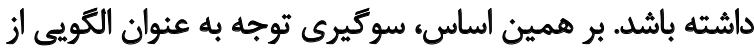

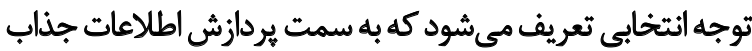

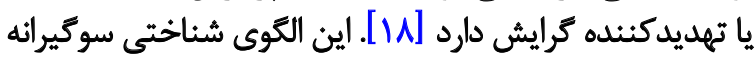

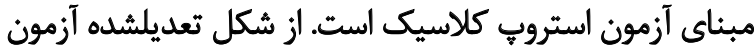

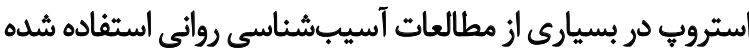

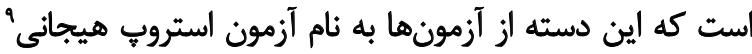

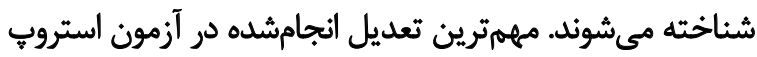

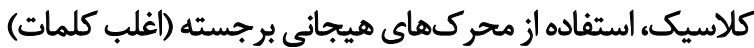

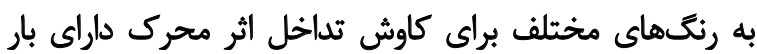

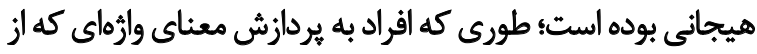

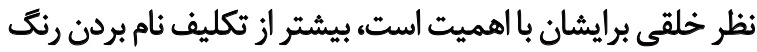

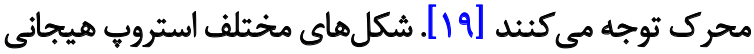

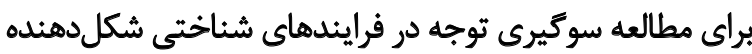

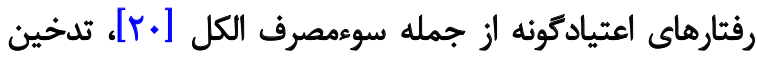

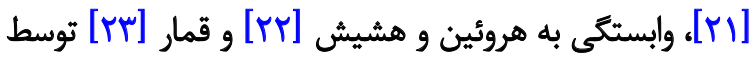

$$
\text { يثروهشكران به كار ترفته شده است. }
$$

آزمون استروب خودكشى •" شكل تعديليافته آزمون استروب

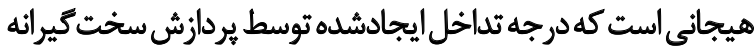

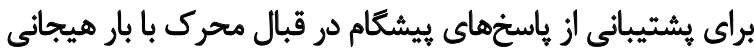

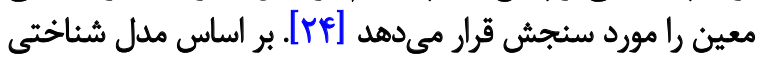

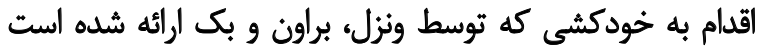

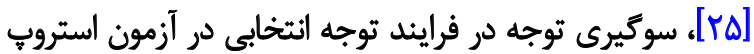

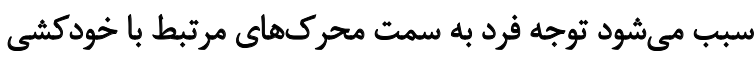

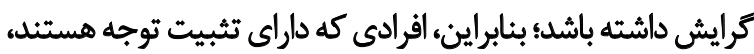

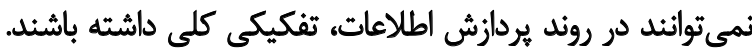

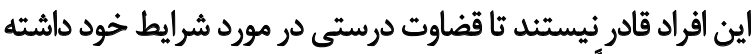

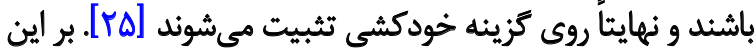

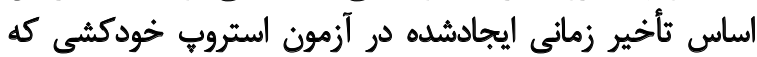

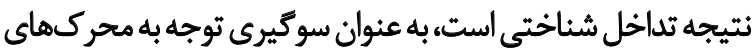

مرتبط با خودكشى در نظر كرفته مىشود [11]

اولين مطالعه روى سوكيرى توجه در بردازش اطلاعات مرتبط

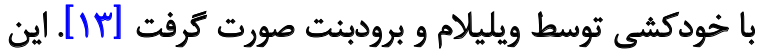

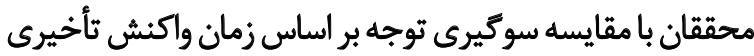

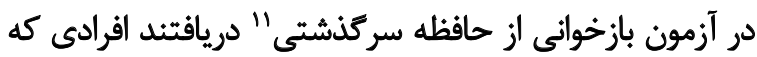

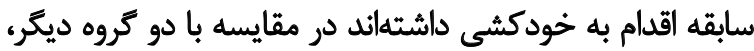

\section{Selective Attention}

9. Emotional Stroop Task (EST)

10. Suicide Stroop Test

11. Autobiographical Memory Retrieval Test
اقدام به خودكشى رو به افزايش است؛ طورى كه در سال عوبها

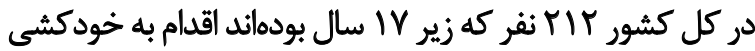

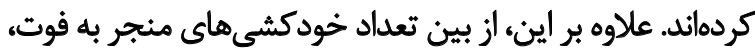

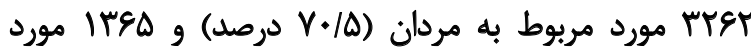

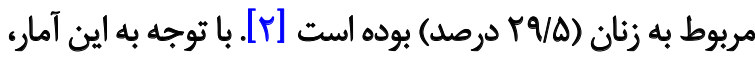

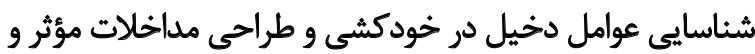

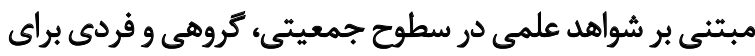

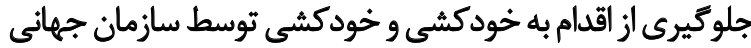

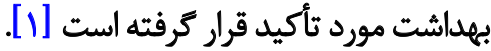

خيشبينى افكار و رفتارهاى خودكشى و روش هائ ارزيابى خطر

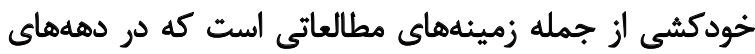

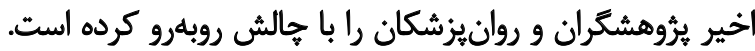

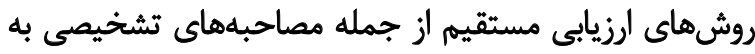

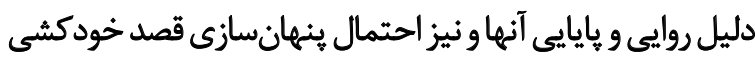

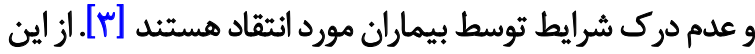
رو سنجشهاى رفتارى و غيرمستقيم به به عنوان مسيرى جائزئين

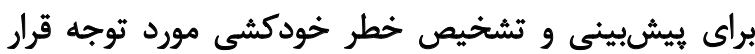

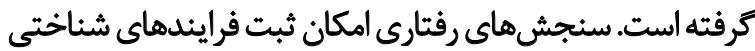

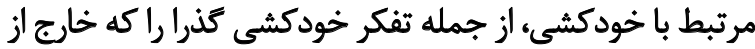

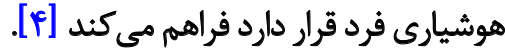

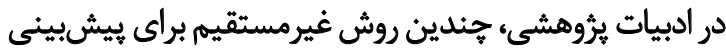

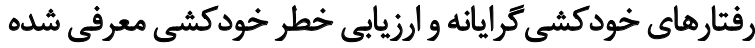

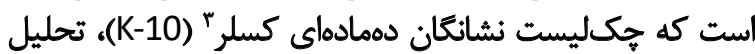

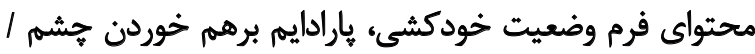

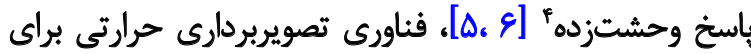

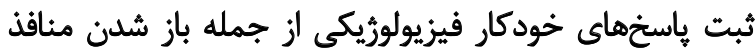

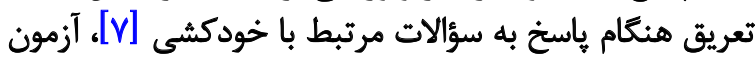

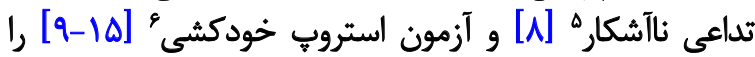

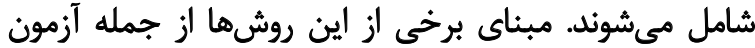

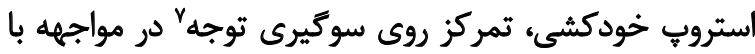

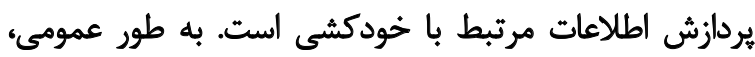

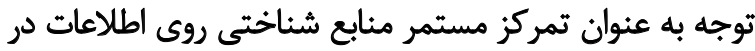

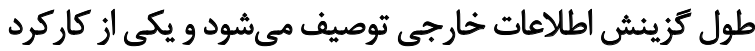

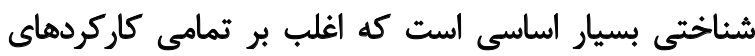

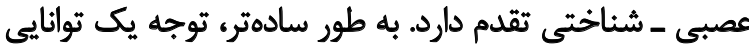

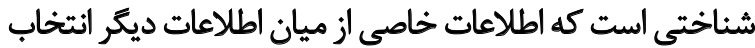

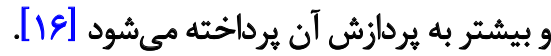

3. Kessler

4. Eye-Blink/Startle Response Paradigm

5. Implicit Association Test

6. Suicide Stroop Test

7. Attentional Bias 


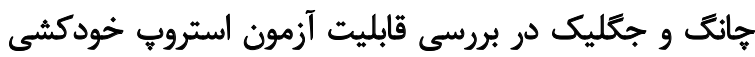

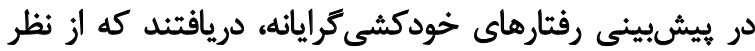

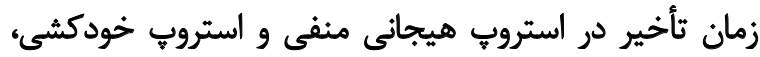

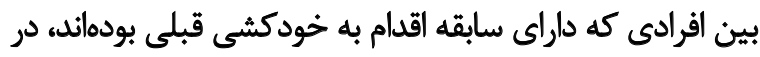

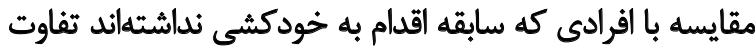

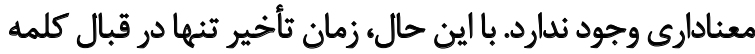

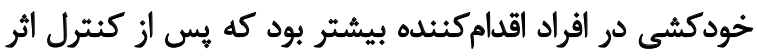
نشانكان افسردكى، اين ثفاوت نيز وجود أنداشت

همجنين، نتايج تحليل ركرسيون لجستيك سلسلهمراتبى

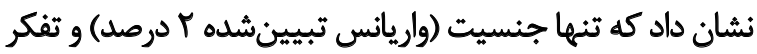

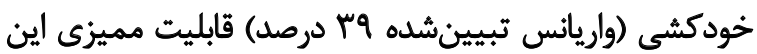

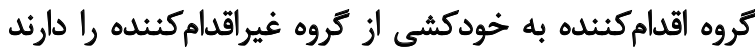

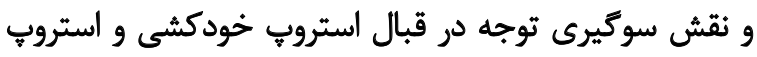

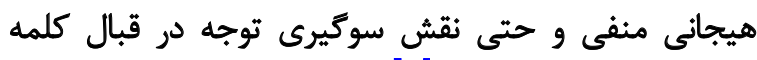

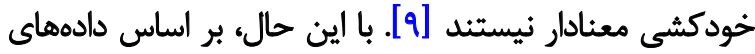

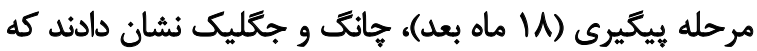

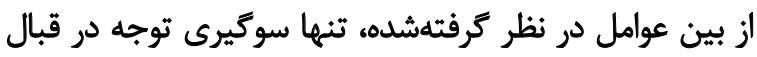

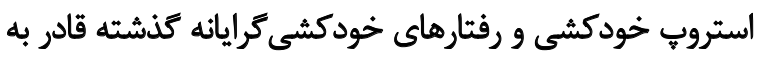

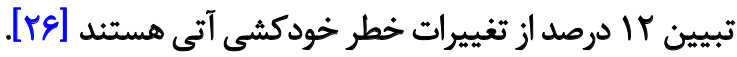

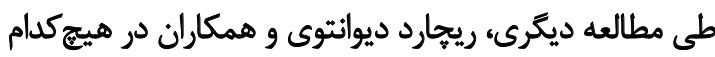

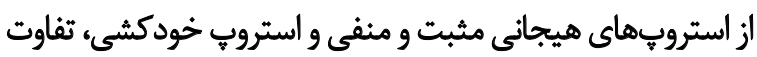

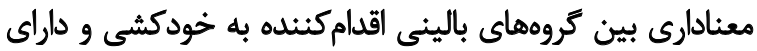

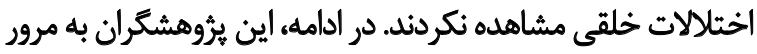

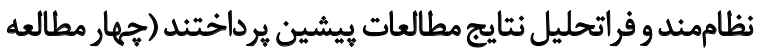

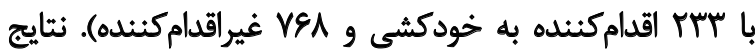

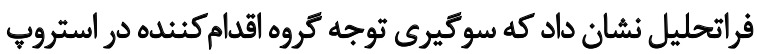

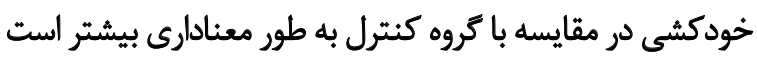

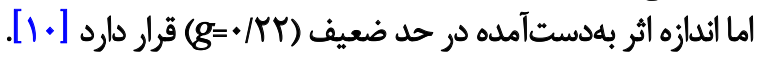

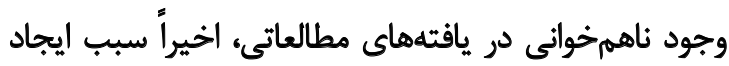

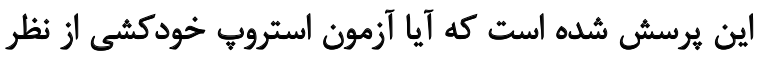

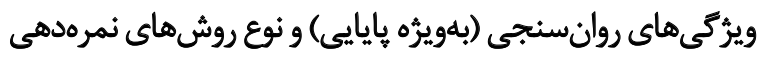

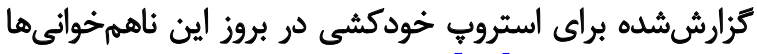

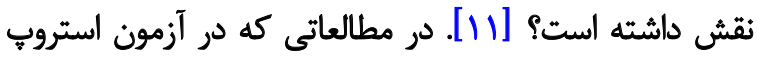

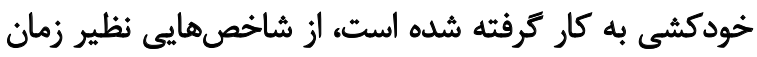

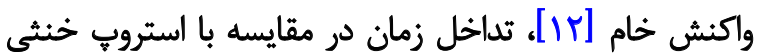

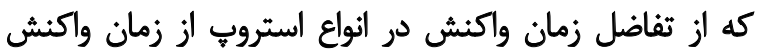

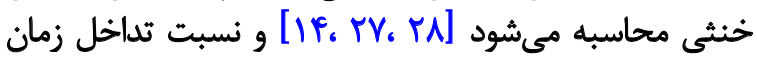

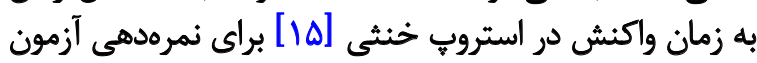

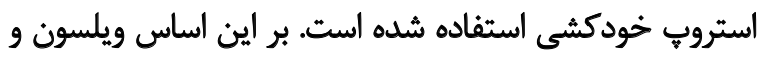

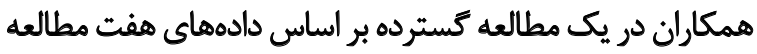

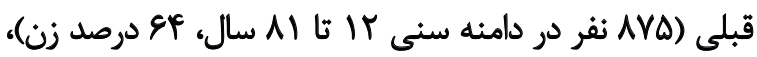

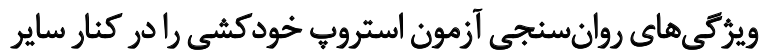

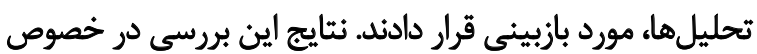

در بازيابى خاطرات شخصى خاص در واكنش به كلمات محرى

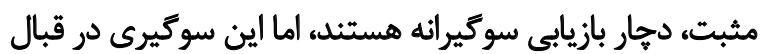

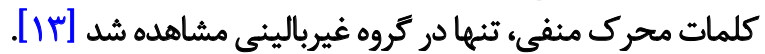

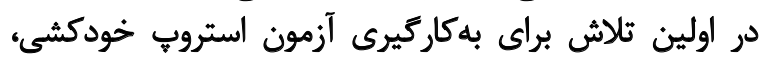

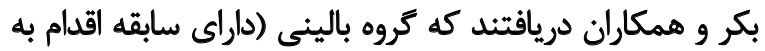

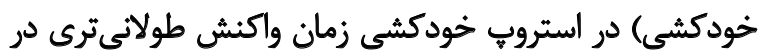

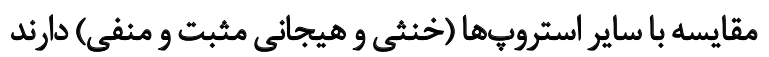

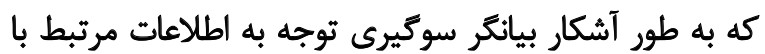

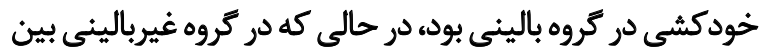

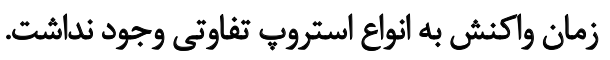

علاوه بر اين، بين سوكيرى توجه و تفكر خودكشى همبستئى

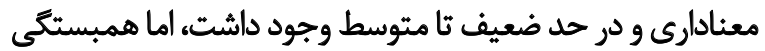

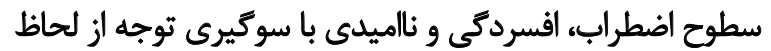

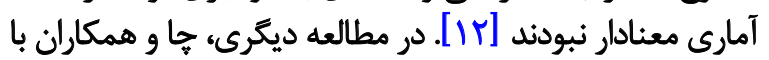

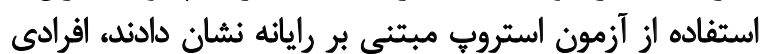

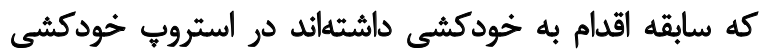

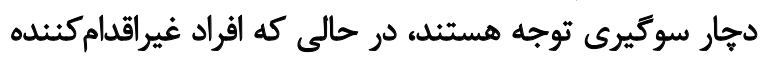

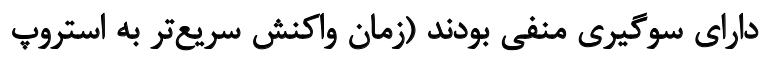

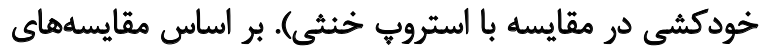

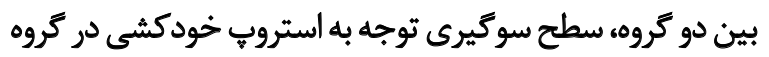

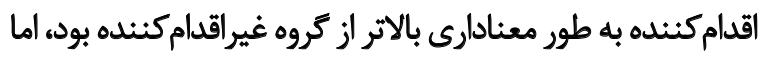

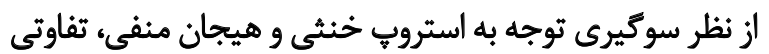

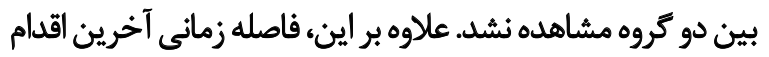

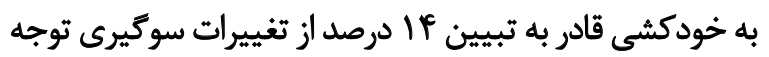

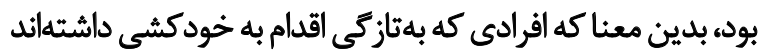

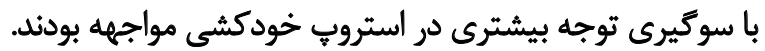

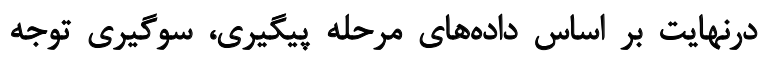

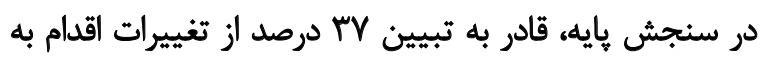

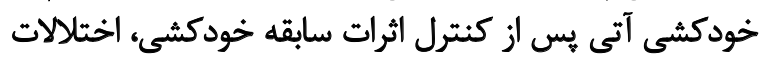

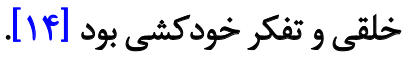

در يروهش ديكرى، استوارت و همكاران دريافتند كه سوكيرى

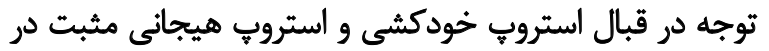

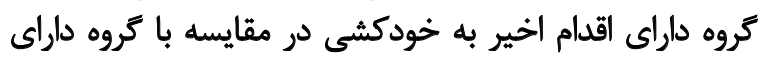

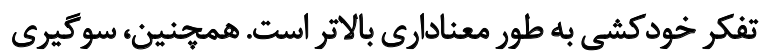

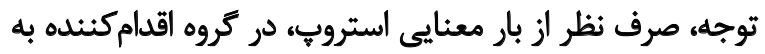

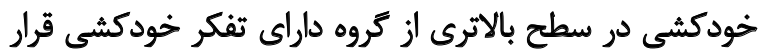

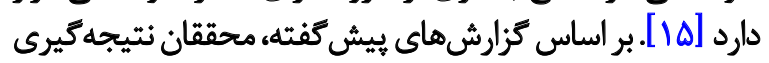

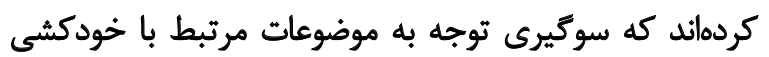

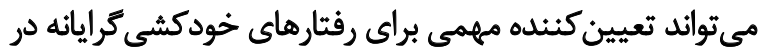

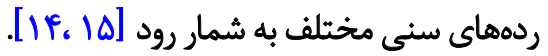

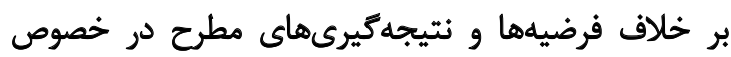

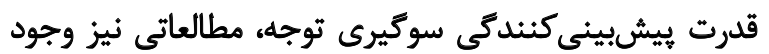

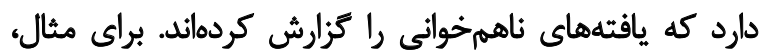




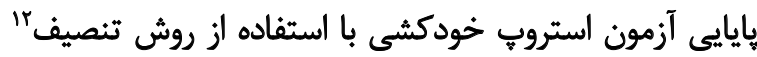

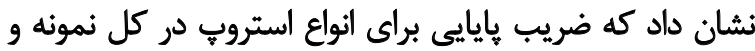

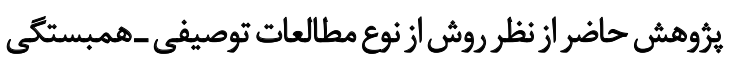

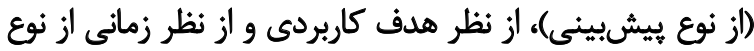

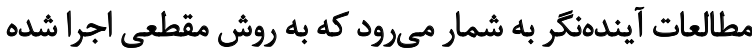

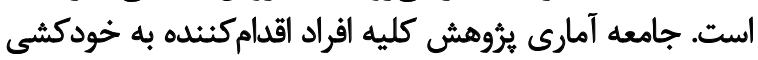

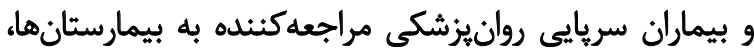

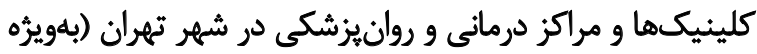

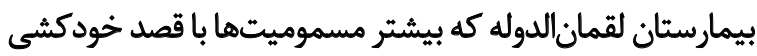

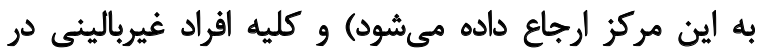

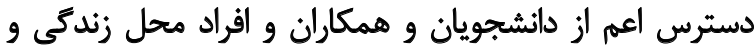

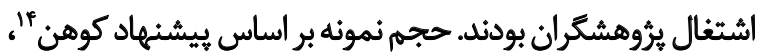

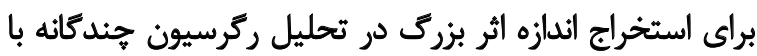

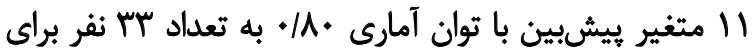

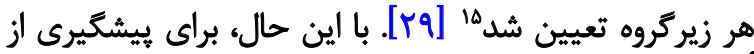

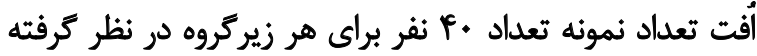

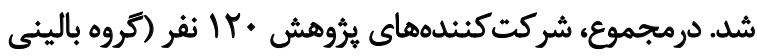

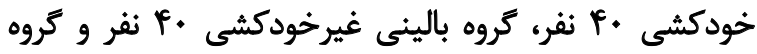

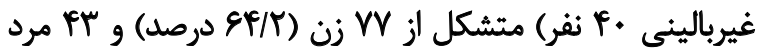

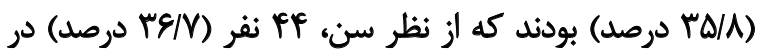

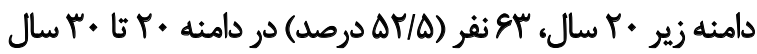

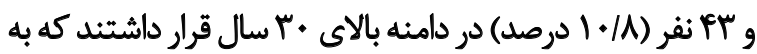
صورت هدفمند و دردسترس از بين جامعه آمارى انتخاب شدرالند. فراوانى و درصد فراوانى ويزگكىهاى جمعيتشناختى نمونه

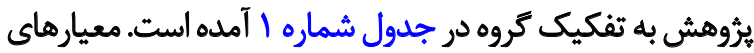

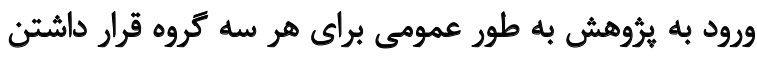

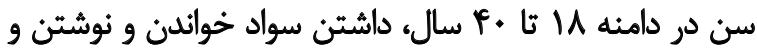

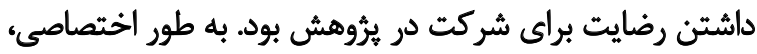

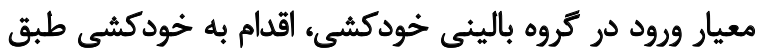

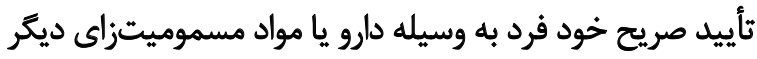

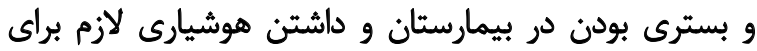

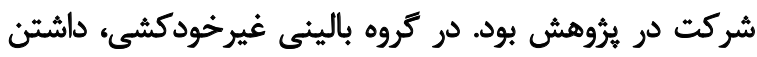

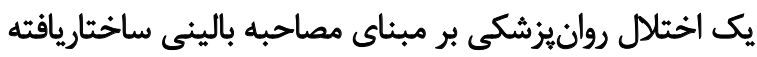
ينجمين ويرايش راهنماي تشخيصى و آمارى اختلالاتلات روائى

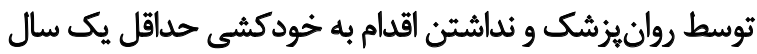

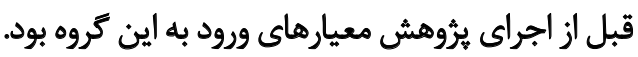

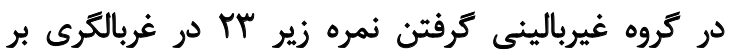

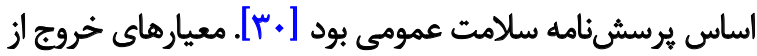

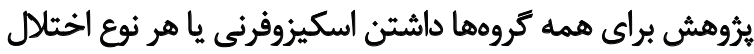

14. Cohen

15. N=22 + تعلاد متغيرهاي بيشيشين

16. Diagnostic and Statistical Manual of Mental Disorders (DSMV-TR)

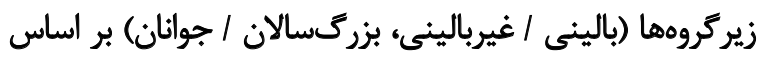

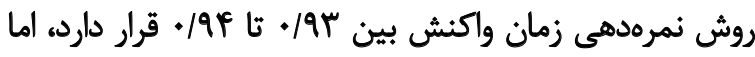

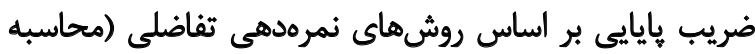
تداخل زمان و نسبت تداخل) در حد بسيار ضعيف قرار داشت نفاضل (محاسبه

همجنين، تنها بر اساس روش نمرهدهى زمان زمان واكنش، تروها

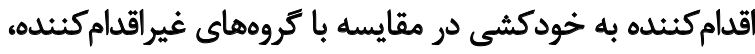

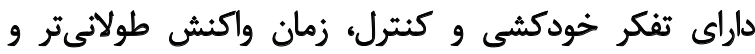

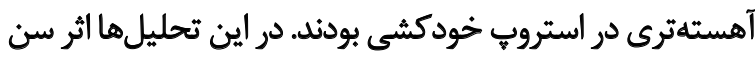

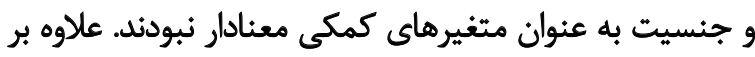

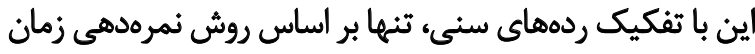

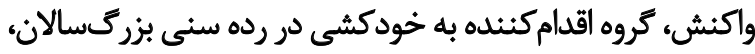

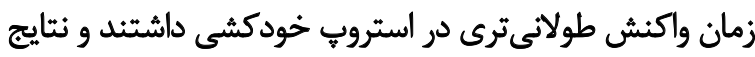

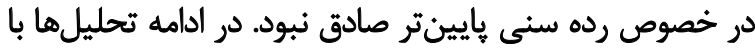

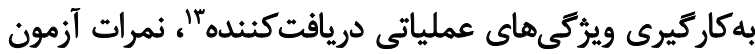

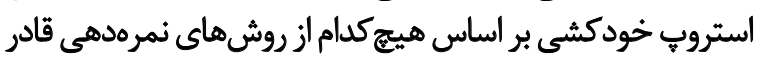

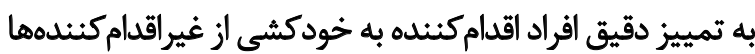

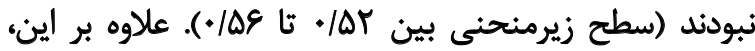

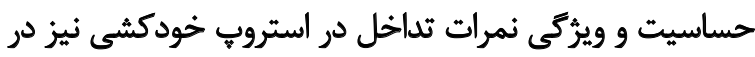

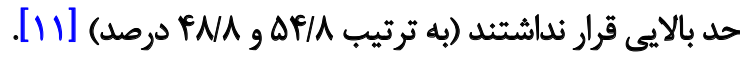
به طور كلى، قابليت سوكيرى توجه در بيشيشينى رفتارهاى

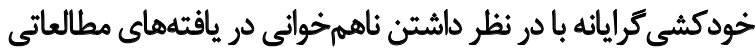

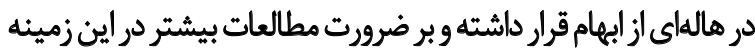

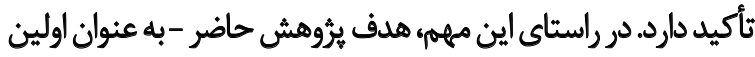

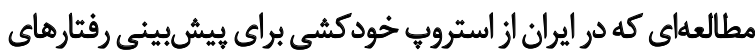

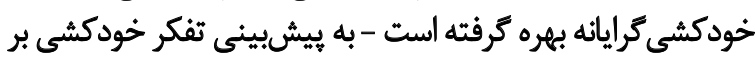

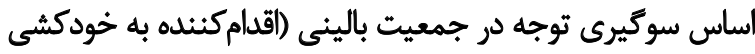

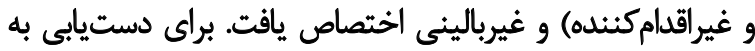

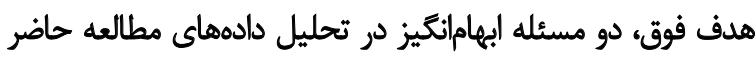

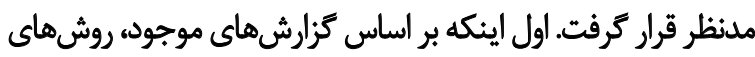

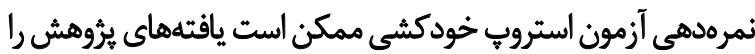

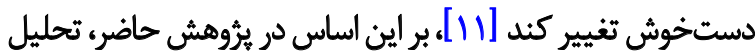

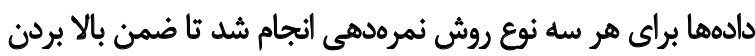

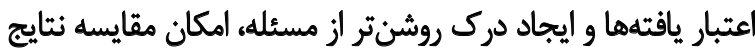

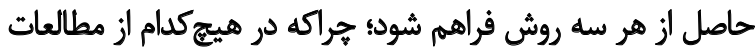

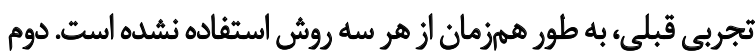

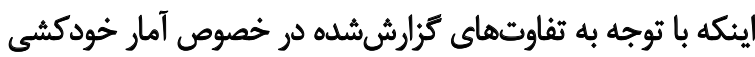

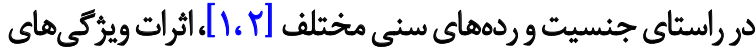
جمعيتشناختى بهويثره سن و جنسيت در تحليل دادهما كنترل شد.

12. Split-Half Reliability

13. Receiver Operating Characteristic (ROC) 


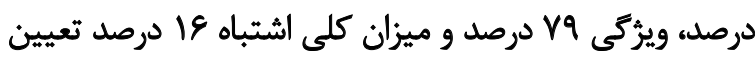

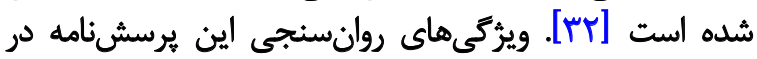

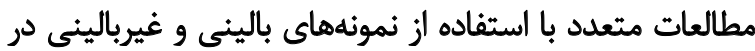

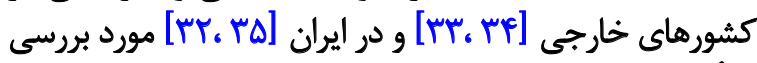
و تأييد قرار كرفته است.

$$
\text { آزمون الستروب هيجاني - نسخهاه خودكشي }
$$

در يُروهش حاضر براى سنجش سوكيرى توجه نسخه

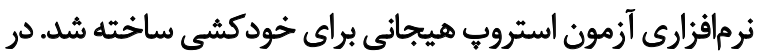

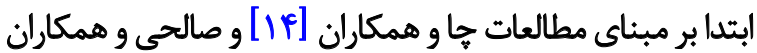

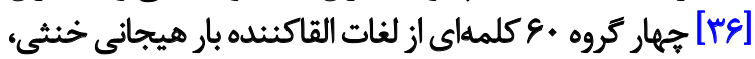

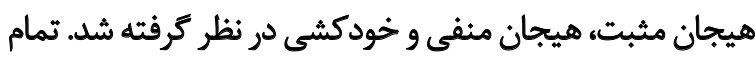

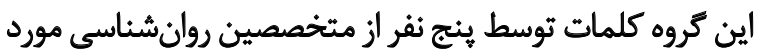

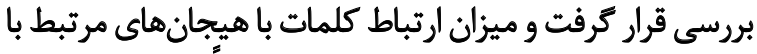

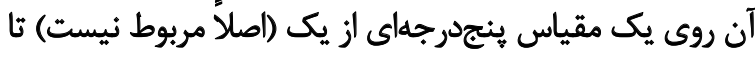

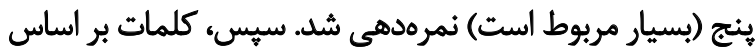

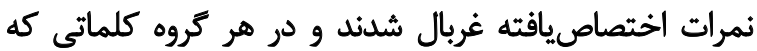

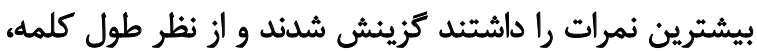
تلفظ و تعداد حروف همتا شدند.

براى به دست آوردن فراوانى تكرار آن در زبان فارسي،

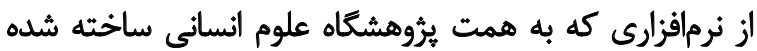

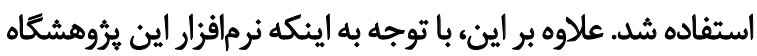

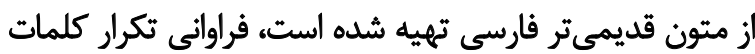

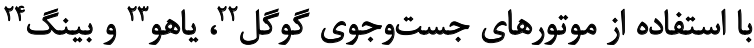

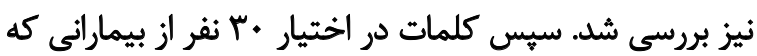

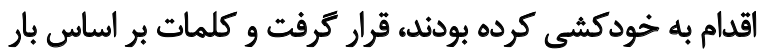

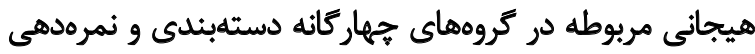

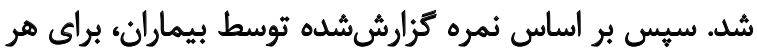

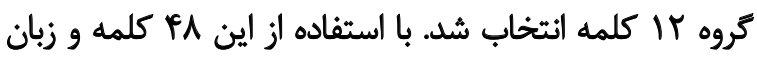

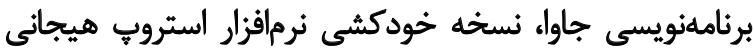

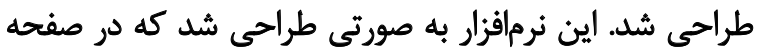

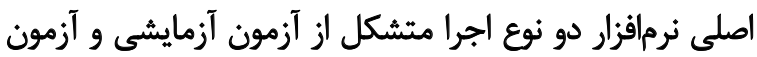

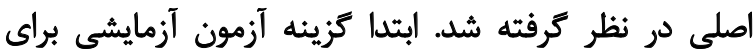

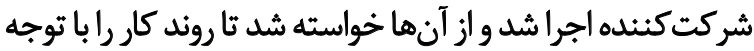

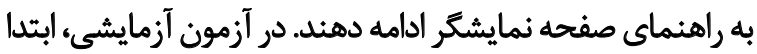

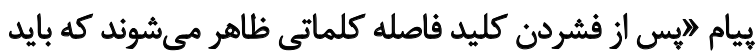

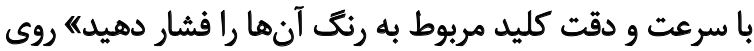
صفحهاى خاكسترى نمايش داده شد.

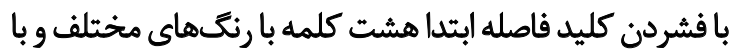

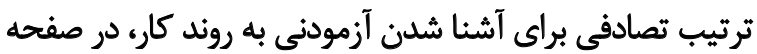

22. www.google.com

23. www.yahoo.com

24. www.bing.com

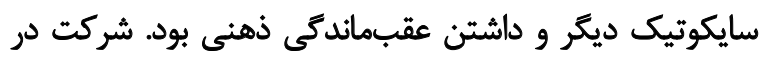

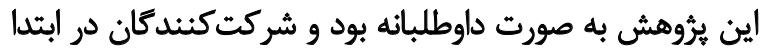

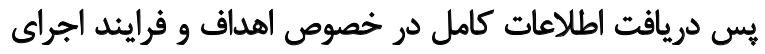

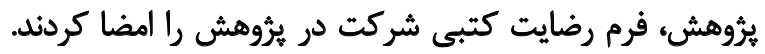

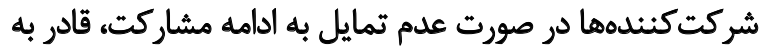

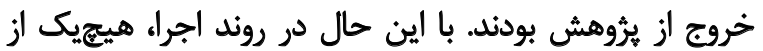

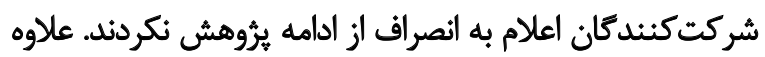

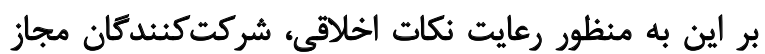

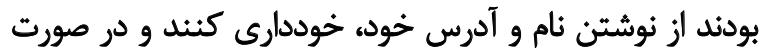

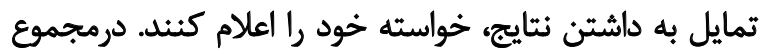

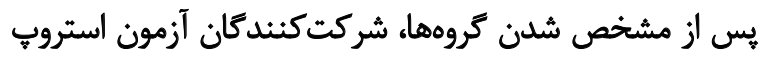

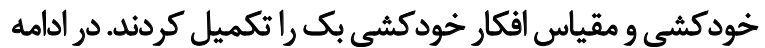

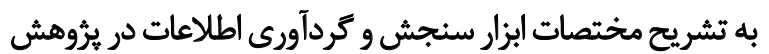
حاضر يرداخته مىشود.

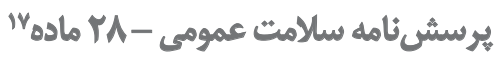
اين يرسشنامه يكى از شناختهشدهترين ابزارهاى غربالكرى در

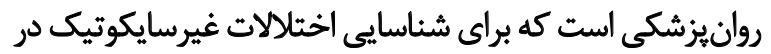

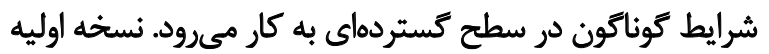

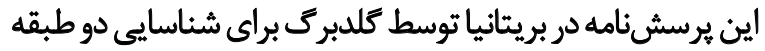

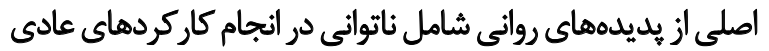

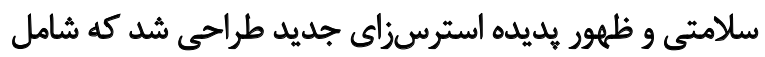

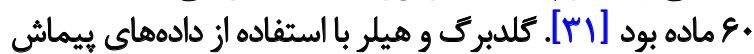

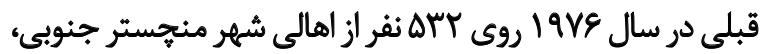

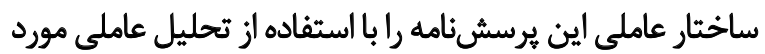

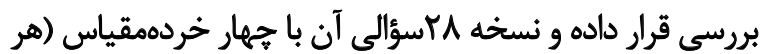

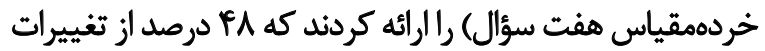

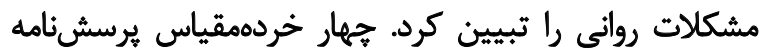

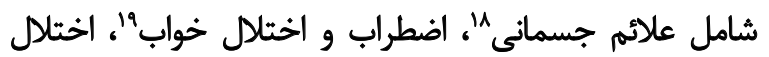

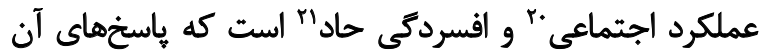

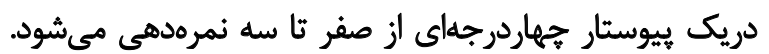

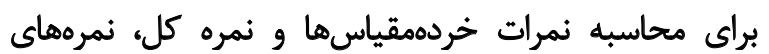

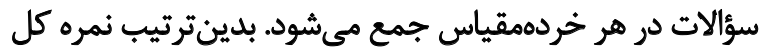

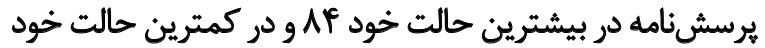
صفر به دست مى آيد [Y]

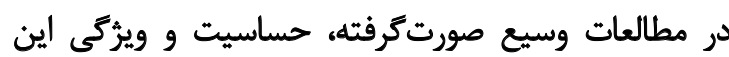

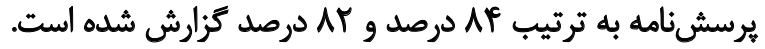

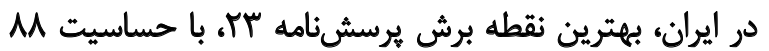

17. General Health Questionnaire - 28 Item (GHQ-28)

18. Somatic Symptoms

19. Anxiety and Insomnia

20. Social Dysfunction

21. Severe Depression 


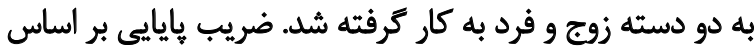

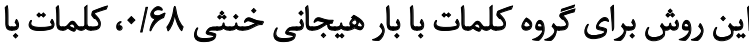

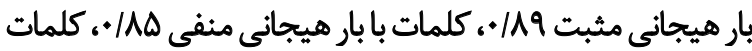

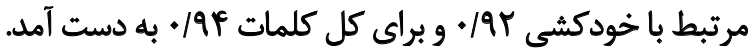

\section{مثياس افكار خُوكشي بكM M}

اين مقياس يك ابزار خودَّزارشى است كه بر اساس آنه شدت

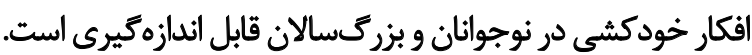

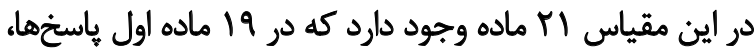

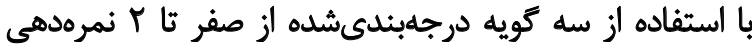

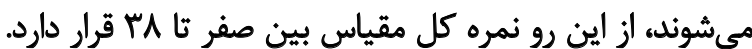

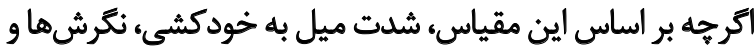

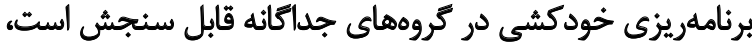

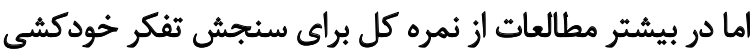

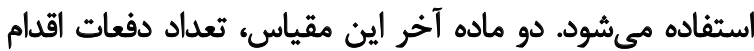
قبلى و جدى بودن قصد در آخرين اقدام را مورد سنجش آندين قرار

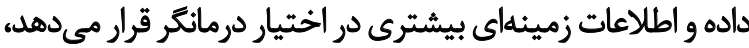
اما در محاسبه نمره كل منظور نمى ئشود. نسخه زبان انغليسى اين مقياس با آزمونهاى استاندارد

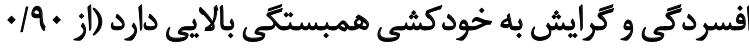

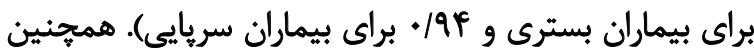

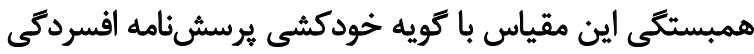

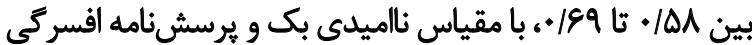

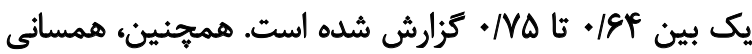

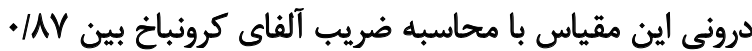

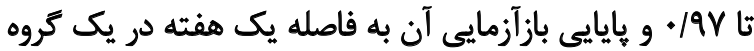

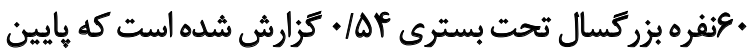

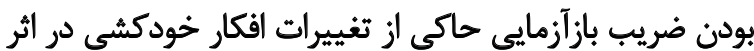

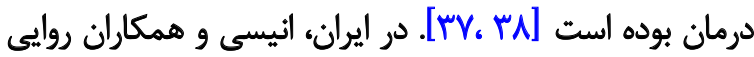

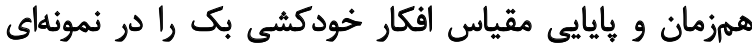

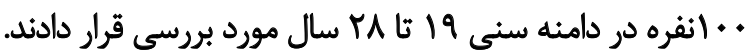

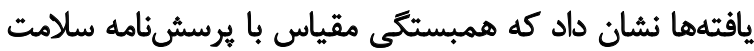

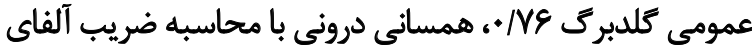

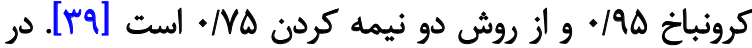

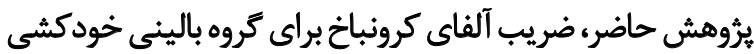

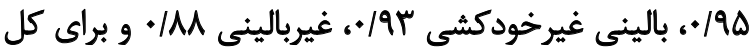

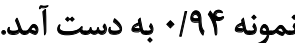

دادههاى كردآورىشده با استفاده از روشهاى آمار توصيفى (مائ

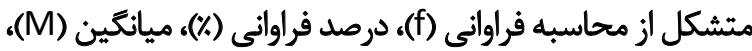

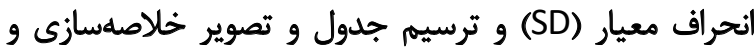

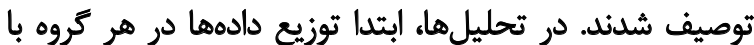

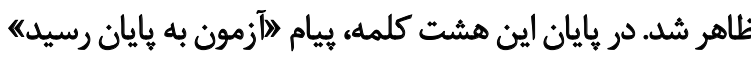

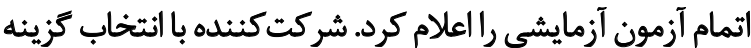

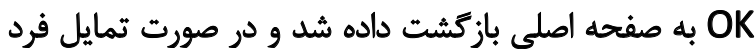

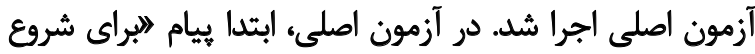

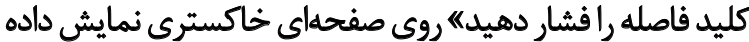
شد. با فشار دادن كليد فاصله،

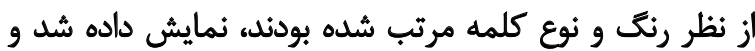

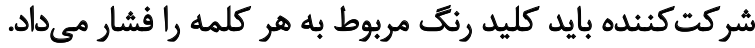

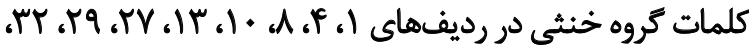

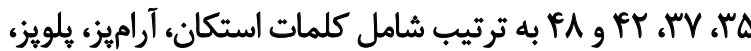

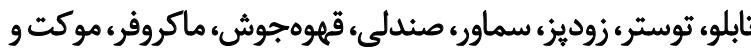

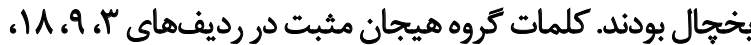

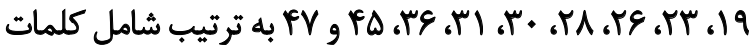

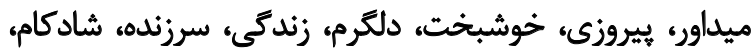
شادمان، كامرواء هميارى و وفادار بودند.

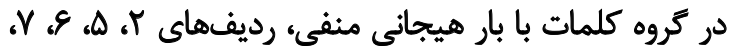

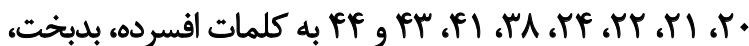

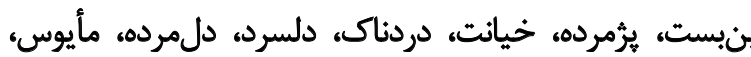

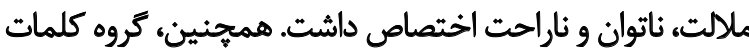

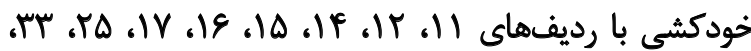
خf rf خودسوزى، رق زدن، قرص برنج

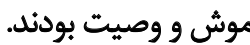

جينش تصادفى كلمات و رنكها از يك شركت بنثنده به

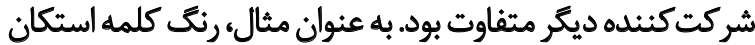

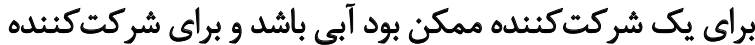

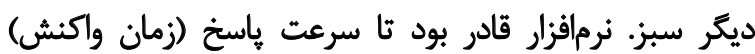

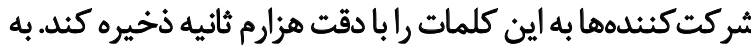

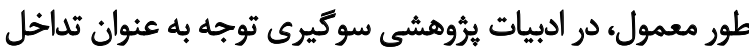

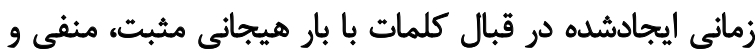

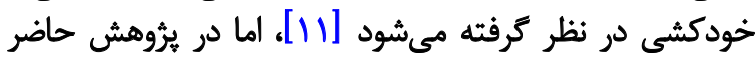

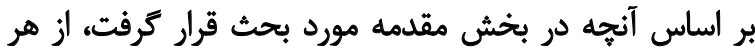

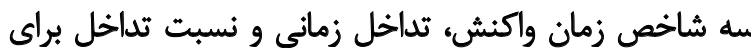

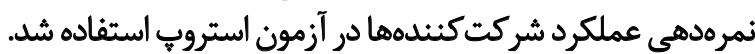

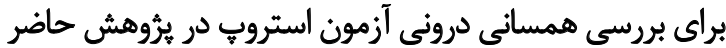

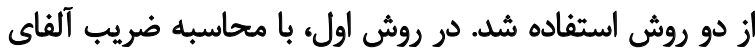

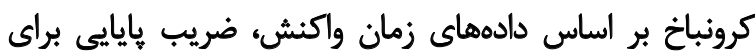

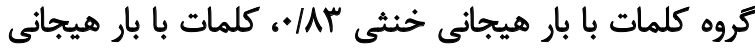

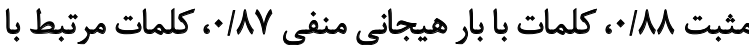

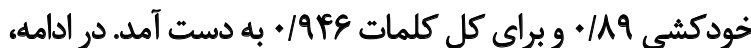

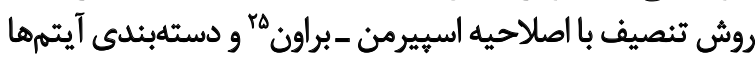




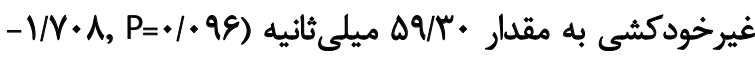

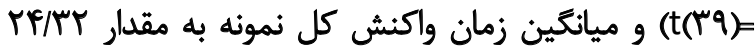

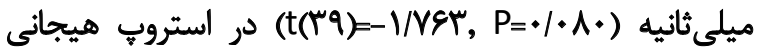

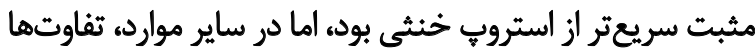

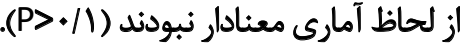

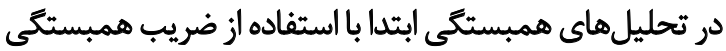

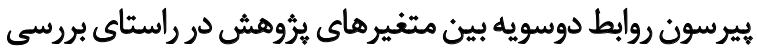

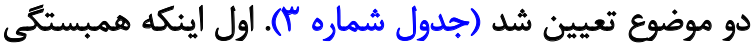

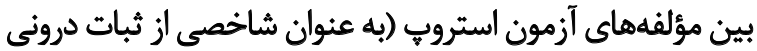

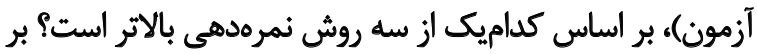

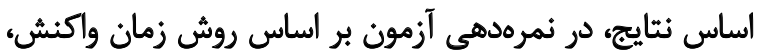

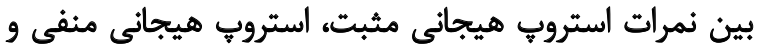

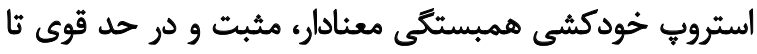

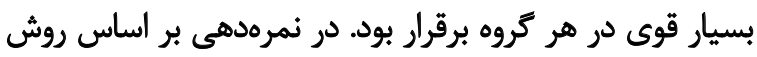

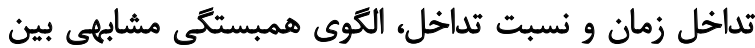

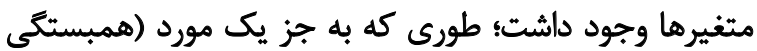

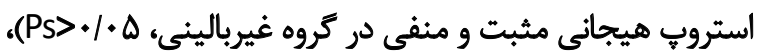

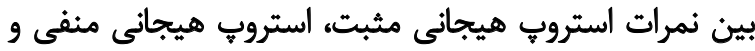

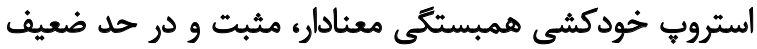

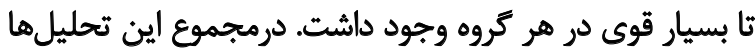

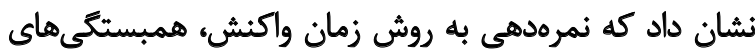

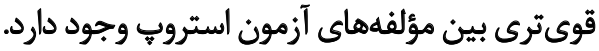

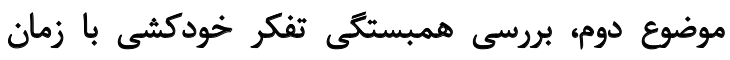

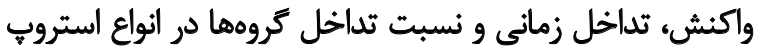

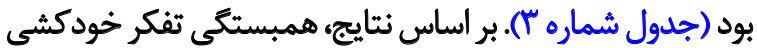

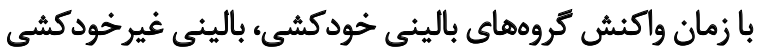

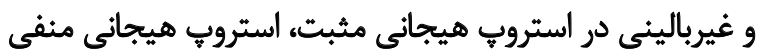

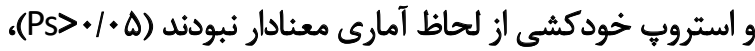

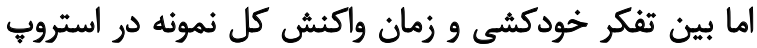

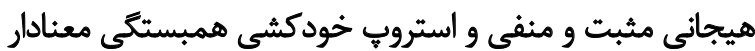

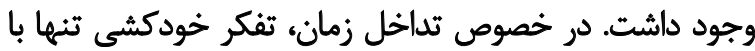

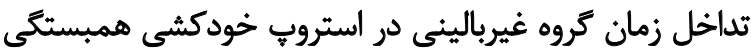

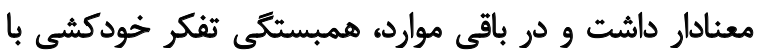

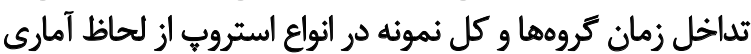

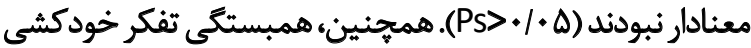

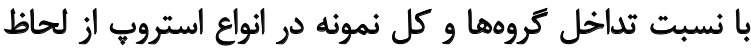

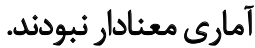

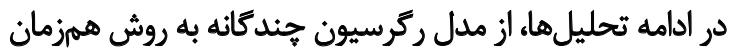

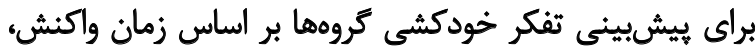

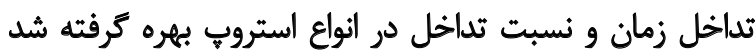

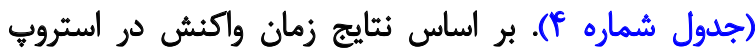

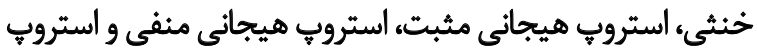
خودكشى قادر به بيشبينى تفكر خودكشى در كروههاى بالينى

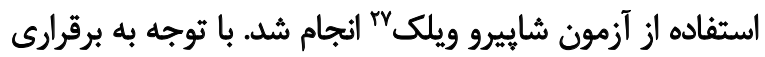

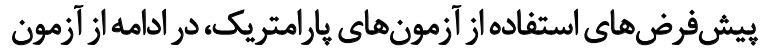

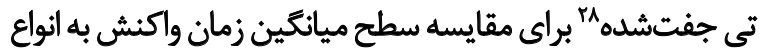

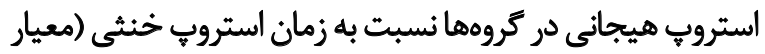

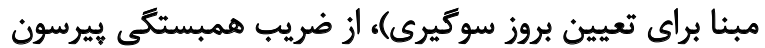

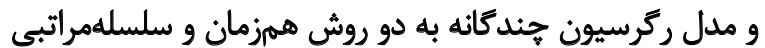

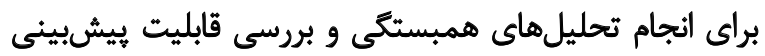

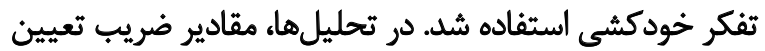

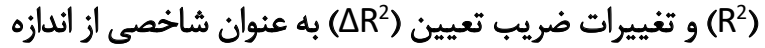

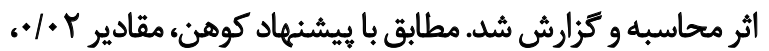

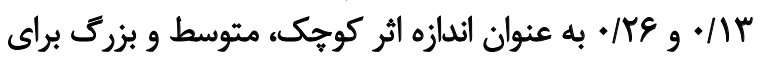

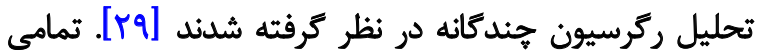

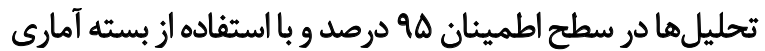

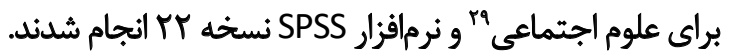

يافتها

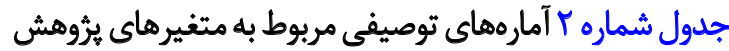

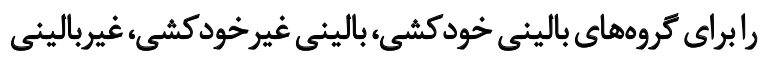

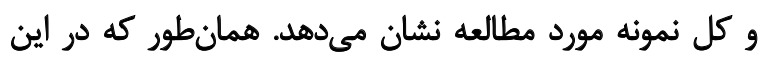

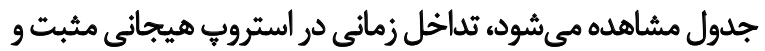

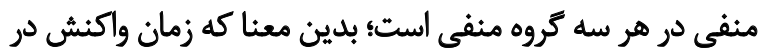

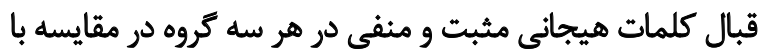

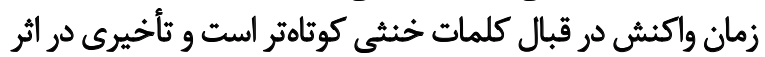

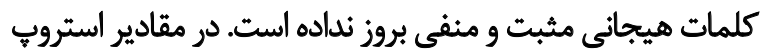

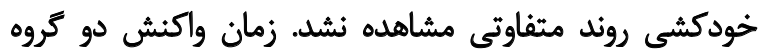

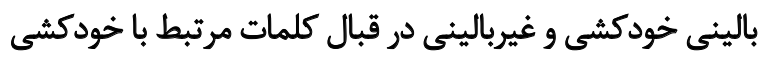

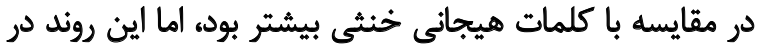

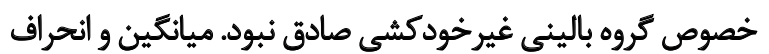

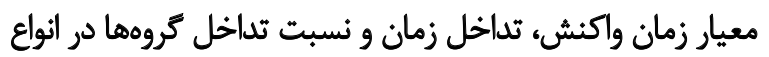

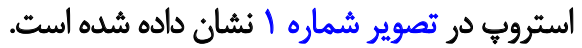

در ادامه، سطوح ميانكين زمان واكنش در استروبه هاى هيجانى

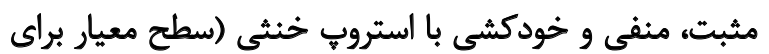

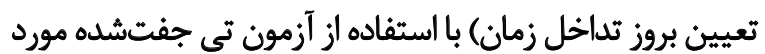

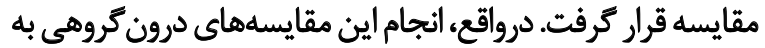

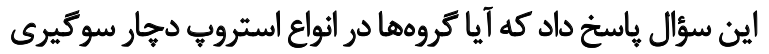

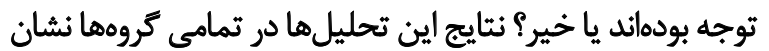

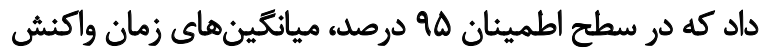

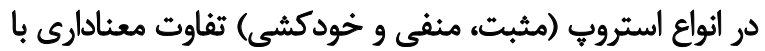

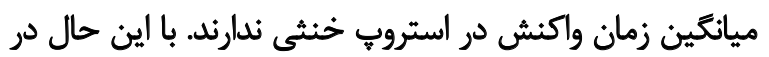

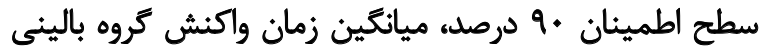

29. Statistical Package for Social Sciences 
تداخل زمان و نسبت تداخل تروهها در انواع استروب بودند. نتايج

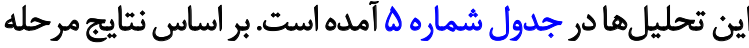

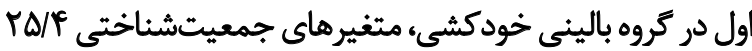
درصد از تغييرات تفكر خودكشى را تبيين كردند (F)

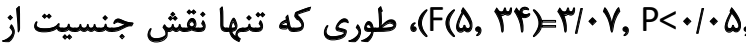

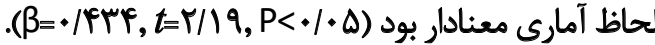
در كروه بالينى غيرخودكشى، متغيرهاى جمعيتشناختى

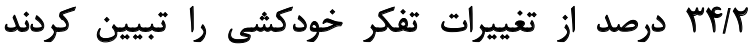

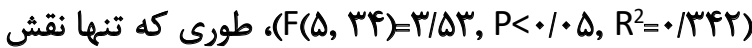

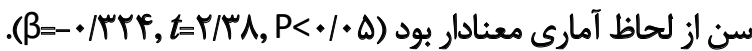

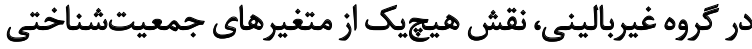

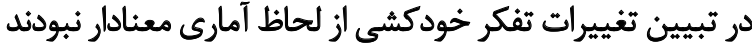

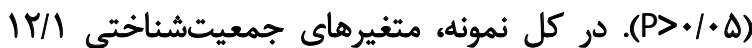

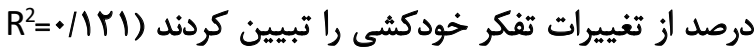

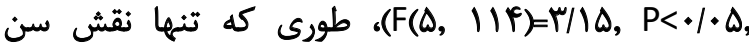

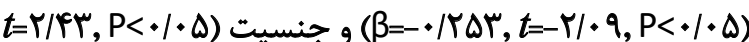
rM,

در مرحله دوم تحليل رگرسيون با اضافه شدن عوامل مربوط

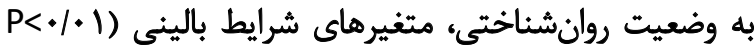

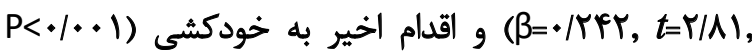

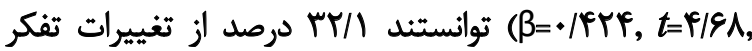

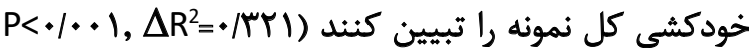
(AF(T, IIT)=rT/TF,

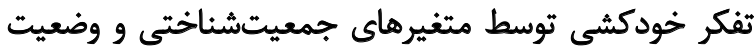

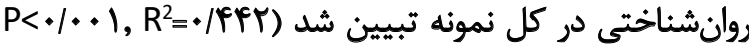

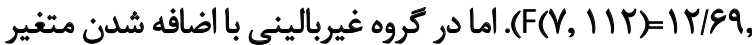

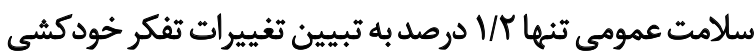

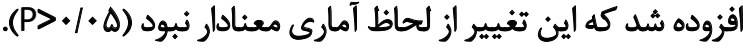

در مرحله سوم تحليل ركرسيون نمرات انواع استروب در سه

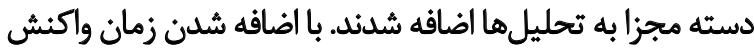

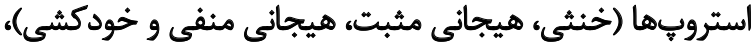

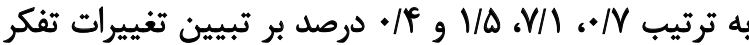

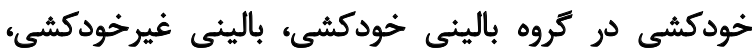

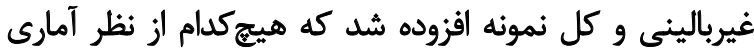

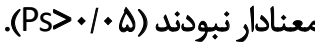

به طور مشابه، با اضافه شدن تداخل زمان استروِها (هيجانى

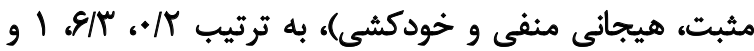

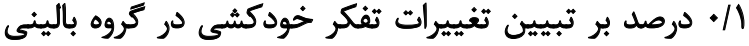

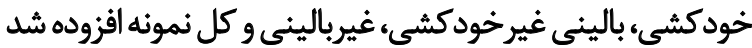

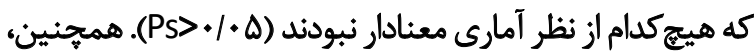

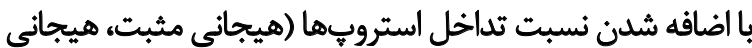

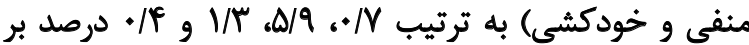

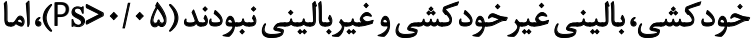

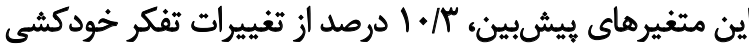

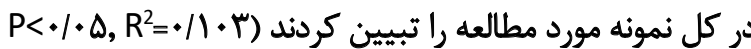

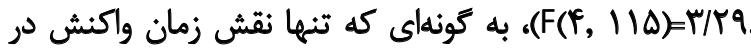

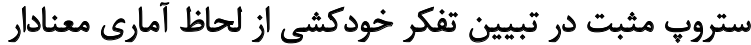

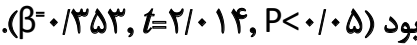

نتايج در خصوص تداخل زمان نشان داد كه تداخل زمان

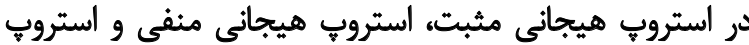

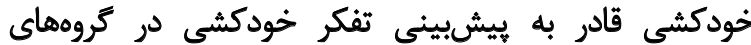

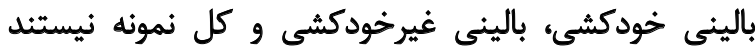

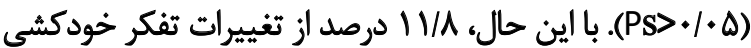

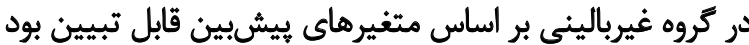

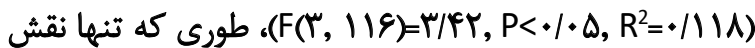

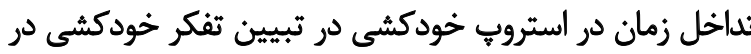

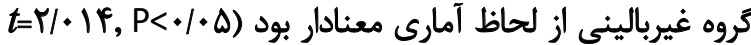

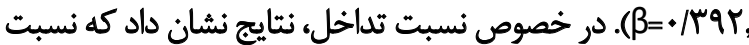

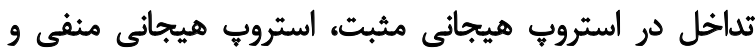

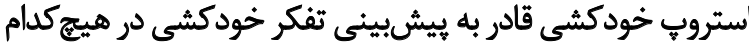

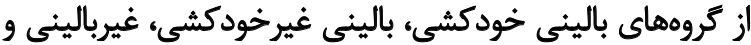

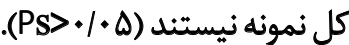

در انتهاى تحليلهاء از مدل ركرسيون جندكائه سلسلهمراتبى

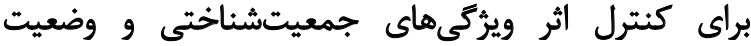

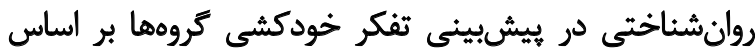

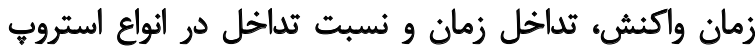

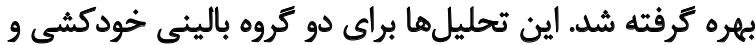

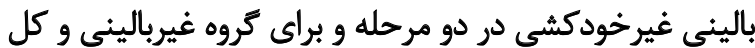

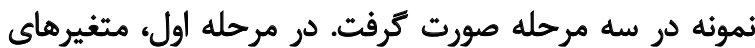

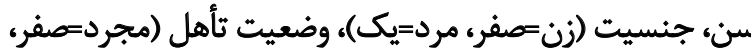

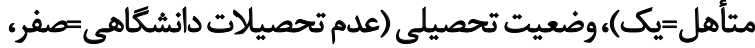

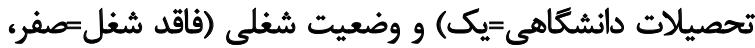

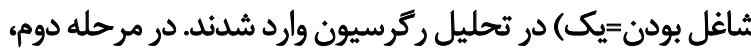

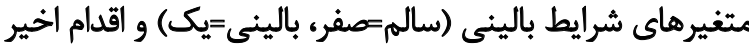

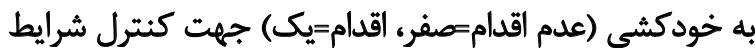

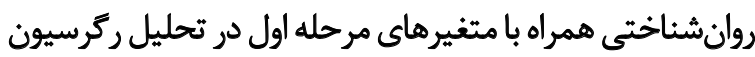
دادهاى مربوط به كل نمونه وارد شدند.

در مرحله دوم كروه غيربالينى، نمرات يرسشنامه سلامت

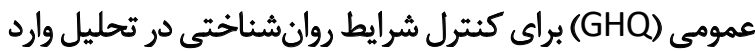

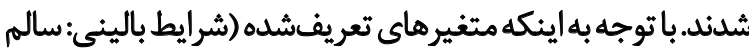

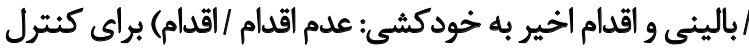

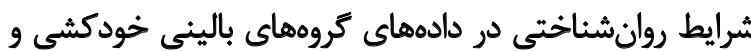

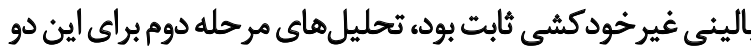

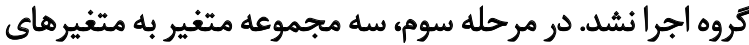

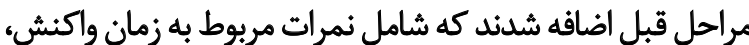


جدول ا. ويثُكى هاى جمعيتشُناختى شركت كنثهها به تفكيك تروه

\begin{tabular}{|c|c|c|c|c|c|}
\hline 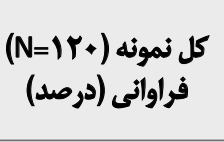 & 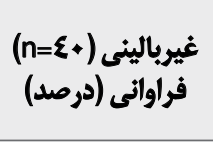 & 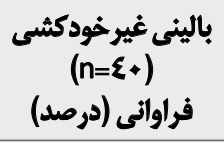 & 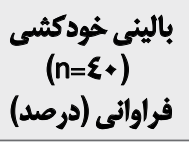 & \multicolumn{2}{|c|}{ ويؤكى } \\
\hline$\mu \varphi(r e / V)$ & $M(P \Delta / \cdot)$ & $r(r+1 \cdot)$ & $\mid f(T \otimes / \cdot)$ & . & \\
\hline$R^{\mu}(\Delta r / \Delta)$ & $r \cdot(\Delta \cdot / \cdot)$ & $r \cdot(\Delta * / *)$ & $\pi(\Delta V / \Delta)$ & .r.r.r. & سن \\
\hline $\mathbb{I r}(1 \cdot / \Lambda)$ & $r(\Delta / \bullet)$ & $\Lambda(r+\%)$ & $r(V / \Delta)$ & >•r سال & \\
\hline$W(g / \pi)$ & $r V(g V / \Delta)$ & $r \cdot(V \Delta / \cdot)$ & $r+(\Delta+/ *)$ & زن & \\
\hline$\mu(r \Delta / \lambda)$ & $\mathbb{H}(M / \Delta)$ & $1 \cdot(T \Delta / \cdot)$ & $r \cdot(\Delta \cdot / \cdot)$ & هرد & جنسيت \\
\hline $\operatorname{Ar}(q 9 / r)$ & $r \cdot(V \Delta / \cdot)$ & $r A(V \cdot / \cdot)$ & $r \Delta(G T / \Delta)$ & هجرد & \\
\hline$\pi(r g / V)$ & $1 \cdot(r \Delta / \cdot)$ & $Q(T r / \Delta)$ & $\mathbb{I}(\Psi T / \Delta)$ & متاهل & \\
\hline$f(m / M)$ & - & $r(V / \Delta)$ & $I(T / \Delta)$ & مطلقه & ل \\
\hline $1(\cdot / 1)$ & - & - & $I(T / \Delta)$ & ازدواج مجدد & \\
\hline$f(\mu / \mu)$ & - & - & $f(1 . \%)$ & ابتدايى & \\
\hline If $(11 / N)$ & - & $8(10 / \cdot)$ & $\Lambda(r \cdot / \bullet)$ & راهنمايي & \\
\hline$r \in(Y M / V)$ & If $(r \Delta / \cdot)$ & $\Delta(I K / \Delta)$ & $V(I V / \Delta)$ & دييرسثان & \\
\hline PI $(M T / Y)$ & $\|(P \Delta / \cdot)$ & $1 \cdot(r \Delta / \cdot)$ & $I r(Y Y / \Delta)$ & دييلم & ثمصيلات \\
\hline$q(V / \Delta)$ & $r(V / \Delta)$ & $r(\Delta / \cdot)$ & $P(1.1)$. & كاردانيى & \\
\hline$M(19 / r)$ & $f(1.1 \cdot)$ & $18(t+1 \cdot)$ & $r(v / \Delta)$ & كارشناسى & \\
\hline$r(T / \Delta)$ & $I(T / \Delta)$ & $I(T / \Delta)$ & $1(T / \Delta)$ & كارشناسى ارشد & \\
\hline $1+\left(N{ }^{\Psi}\right)$ & $I(T / \Delta)$ & $f(1+\%)$ & $\Delta(I r / \Delta)$ & بيكار & \\
\hline "w $\left.\left({ }^{\mu}\right) / V\right)$ & $1 \cdot(r \Delta / \cdot)$ & $\pi(r+1 \cdot)$ & $18(t * 1 *)$ & شاغل & \\
\hline$\Delta H(F Y / T)$ & $\operatorname{Tr}(\Phi V / \Delta)$ & $\mathbb{I r}(T / \Delta)$ & $\operatorname{Ir}(M / \Delta)$ & دانش آموز/لانشجو & وضعيت شغلى \\
\hline$M(\mid \Delta / \cdot)$ & $r(\Delta / \cdot)$ & $1 \cdot(r \Delta / \cdot)$ & $\varepsilon(\mid \Delta / \cdot)$ & خانهدار & \\
\hline $1(\cdot / A)$ & - & $1(T / \Delta)$ & - & اززكار|فتّاده & \\
\hline
\end{tabular}

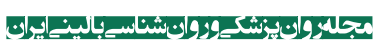

سوكيرى توجه در كروه باليني خودكشي بارزتر است.

مقايسه زمان واكنش در استروب هيجانى مثبت و منفي و

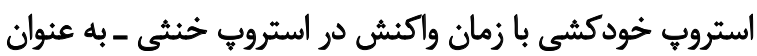

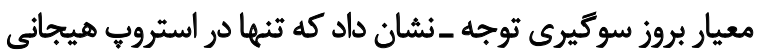

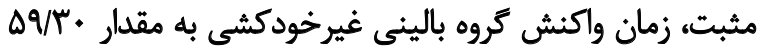

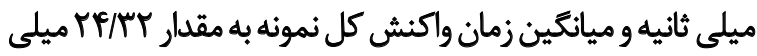

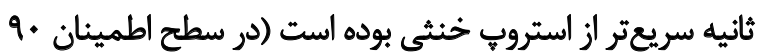

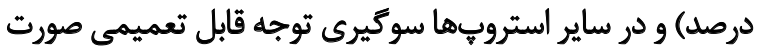

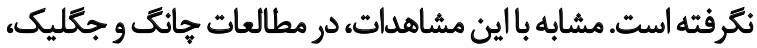

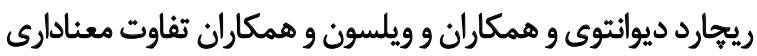

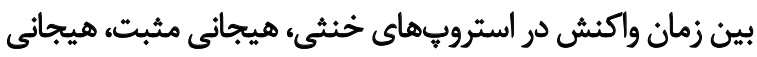

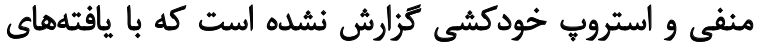

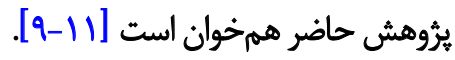

تبيين تغييرات تفكر خودكشي در كروه بالينى خود كشي، بالينى

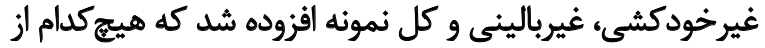
نظر آمارى معنادار نبودند (هs> (Ps). \&) هدف اصلى يُروهش حاضر يّشبينى تفكر خود كشى بر اساس

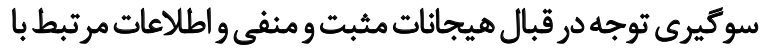

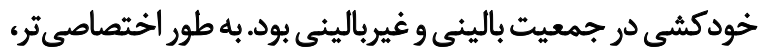

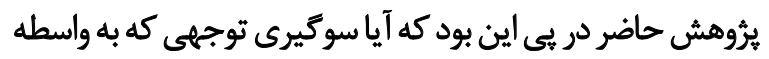

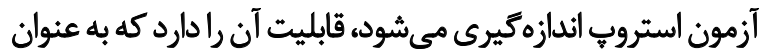

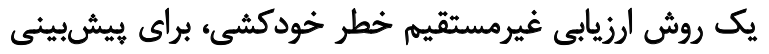

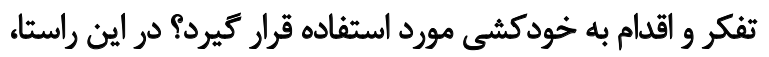

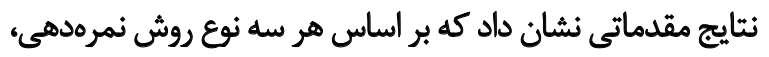


جدول r. ميانكين و انحراف معيار متغيرها به تفكيك كروه

\begin{tabular}{|c|c|c|c|c|}
\hline 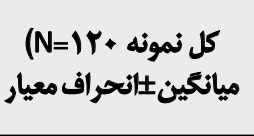 & 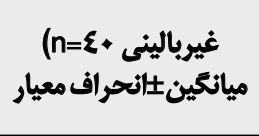 & 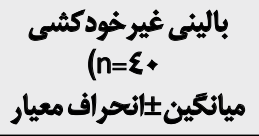 & 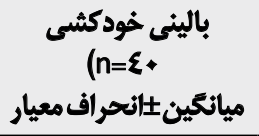 & متغير \\
\hline$M T / E V \pm V / T 1$ & 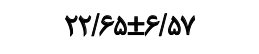 & $r \Delta / A \Delta \pm V / V Y$ & MT/AY $\pm V / M T$ & سن سال) \\
\hline- & $|r / g r \pm \Delta / A|$ & - & - & سلامت عمومى GHQ-YA) \\
\hline$Q \Delta r / Q U \pm r+\Delta / M$ & NET/YA & qRT/IIIYIr/AV & 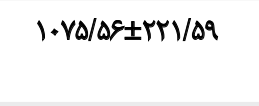 & ميانكين زمان واكثش در آزمون استروب \\
\hline 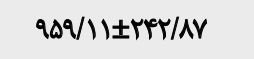 & $N E T / V \Delta \pm I Y \cdot \mid 81$ & $q P Y / \cdot 1 \pm Y \cdot V / 8 q$ & $1 \cdot V \cdot / \Delta V \pm T Y \cdot 1 \cdot 8$ & زمان واكنش در استروب خنثي \\
\hline 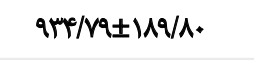 & $\Lambda \Delta \Delta / V A \pm I I F / M$ & $M T / M I \pm \mid \& F / .9$ & 1. $Q Y / N E \pm T \cdot N 8$. & زمان واكنش در استروب هُبت \\
\hline 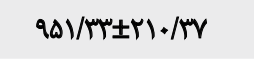 & NAT/gI士IIr/gr & 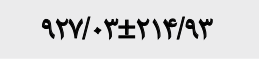 & $1.8 T / M f \pm M r F / .1$ & زمان واكتش در استروب منفى \\
\hline$q V \cdot N \cdot \pm \pi m / A V$ & Neq/qV \pm qV/F. & QTNEVITTNIV & $11 \cdot r / 48 \pm$ refleg & زمان واكش در استروب خودكشى \\
\hline- - /APIITP/qq & $-\cdot / \& \Psi \pm \Delta \Delta / \cdot \Lambda$ & $-r / \Delta r \pm r+q / r$ & glgetq./AY & تداخل زمائى در آزمون استروب هزارم ثانيه) \\
\hline$-M P / M T \Delta \pm \mid Q I / / T$ & $-V / q e 9 \pm E e / 1 r$ & $-\Delta q / r+r \pm Y / Q / F F$ & $-\Delta / N \cdot \Delta \pm I T H / T r$ & تداخل زماني در استروب مثبت \\
\hline$-V / N A F \pm I T q / A q$ & $-. / 1 \Gamma \varphi \pm V \cdot / r \Delta$ & $-10 / 9 W \pm 19 \varepsilon / 99$ & -V/TrIIAV/q & تداخل زمائي در استروب منفىى \\
\hline$|W / \Delta A \pm| \varepsilon \cdot / \mu^{m}$ & $g / \pi \mid \pm \lambda V / \mu$ & $-r / m r V \pm r r \cdot 1 \cdot 1$ & $r T / M V \pm I T+/ V E$ & ثلاخل زماني در استروب خودكشى \\
\hline$+1++4 r \pm+1.9$ & $+1 *+4 V \pm * 1.8$ & $-+1++r q \pm \pm / 11 r$ & $+/+A V \pm+1+1$ & نسبت تداخل در أزمون استروب \\
\hline$-. /+14 t \pm+/ * 1$ & $-+1+.81 \pm+1+\gamma$ & $-+/+r T V \pm \cdot / 1 T$ & $+1+\cdot 1 \Delta \pm \cdot / 11 r$ & نسبت تداخل در استروب مثبت \\
\hline$. / * 114 \pm * / 1$ & $\%+\cdot \mu \pm \cdot / \cdot 1$ & $\%+\cdot r v \pm+/ 1 \mu$ & $-\bullet / \cdot+\Delta f \pm \cdot / \cdot \lambda$ & نسبت تداخل در استروب منفى \\
\hline$*+\% 11 \pm \cdot / 1 r$ &.$/ \cdot|\Delta A \pm \cdot / 1|$ & $. / \cdot \mid V^{\mu} \pm \cdot / 1 \Delta$ & $\cdot / *+\cdot \pm \cdot / M$ & نسبت تداخل در استروب خودكشى \\
\hline V/9r"INA9 & $r / T \Delta \pm r / T q$ & $\Delta / 9 . \pm g / A \mu$ & $10 / \Delta \Delta \pm V / \% q$ & تفكر خودكشى \\
\hline
\end{tabular}

خود كشى و توجه انتخابى به سمت نشانههاي مرتبط باخودكشى كي

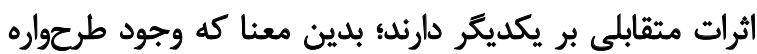

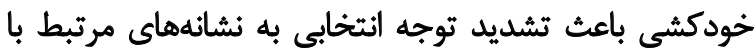

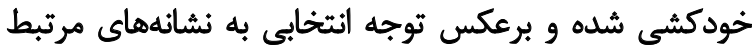

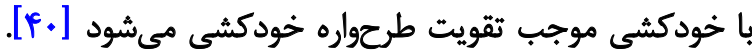

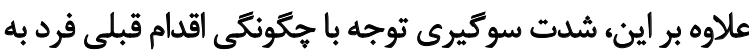

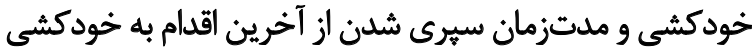
نيز در ارتباط است [IF]

سوكيرى توجه ممكن است نقش قابل ملاحظهاى در

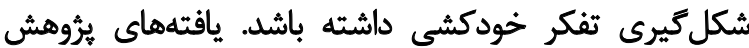

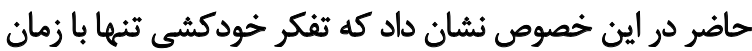

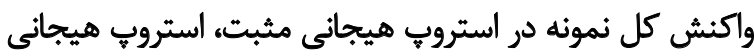

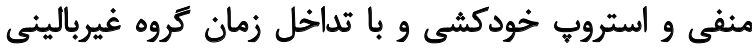

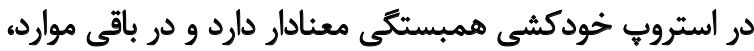

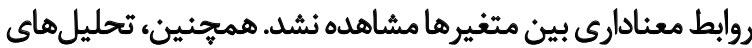

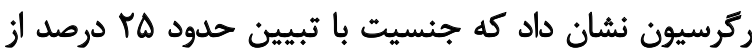

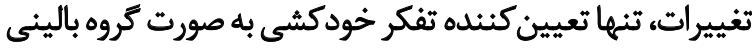

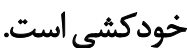

اين شواهد نشان مىدهد كه بروز سوكيرى توجه در بيشتر

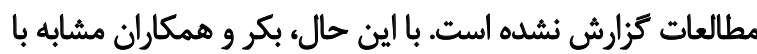

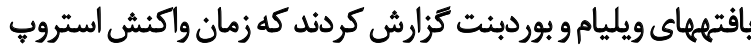

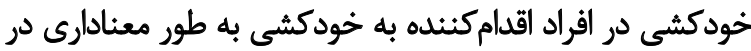

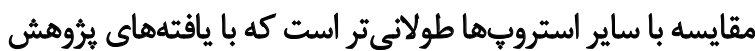

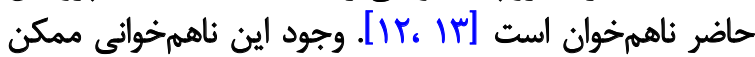

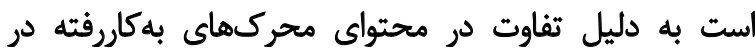

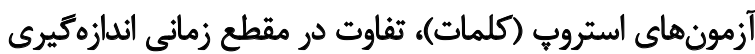

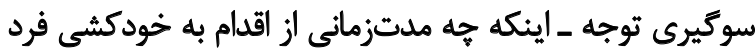

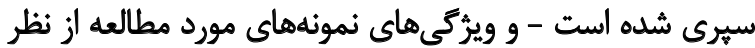

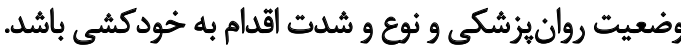
در تشريح علل سوكيرى توجه يس از اقدام به خودكشي، بكر

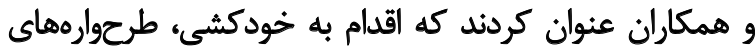

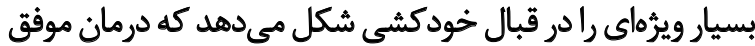

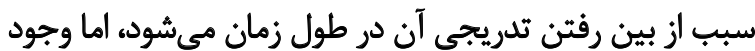

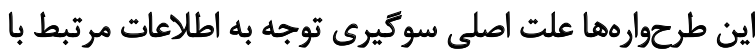

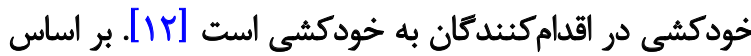

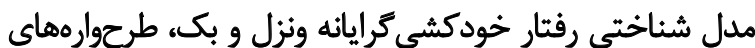




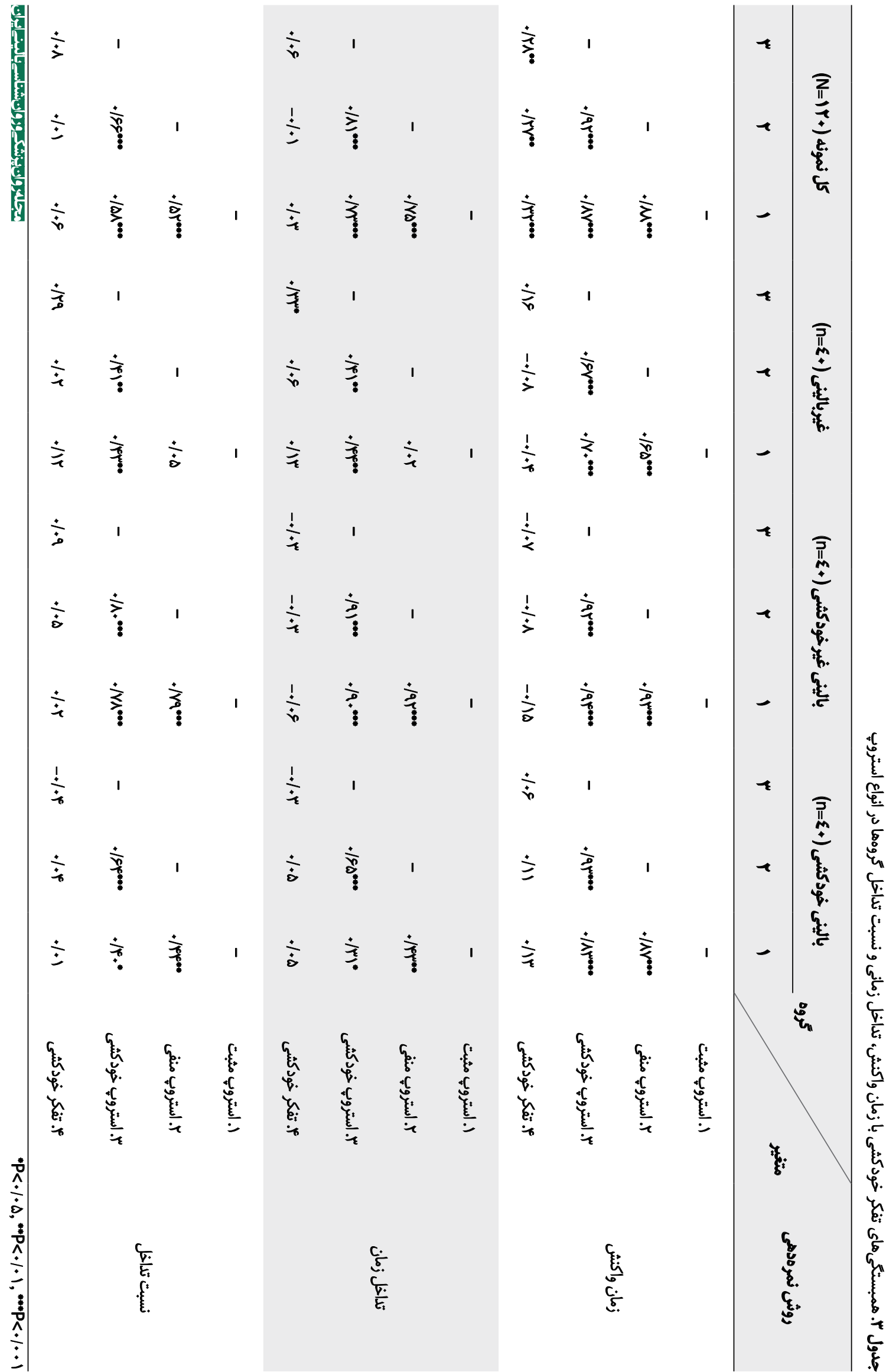




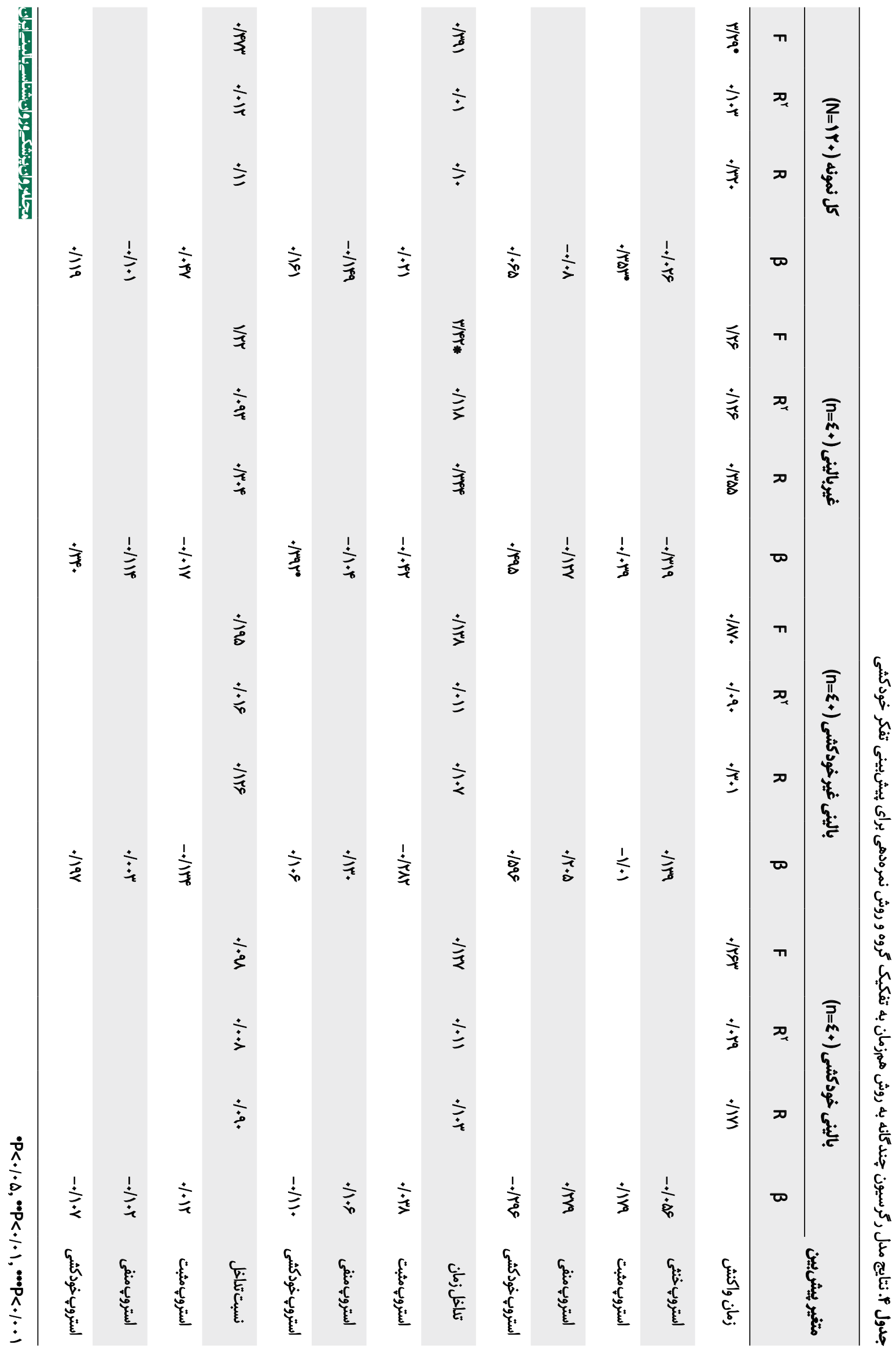




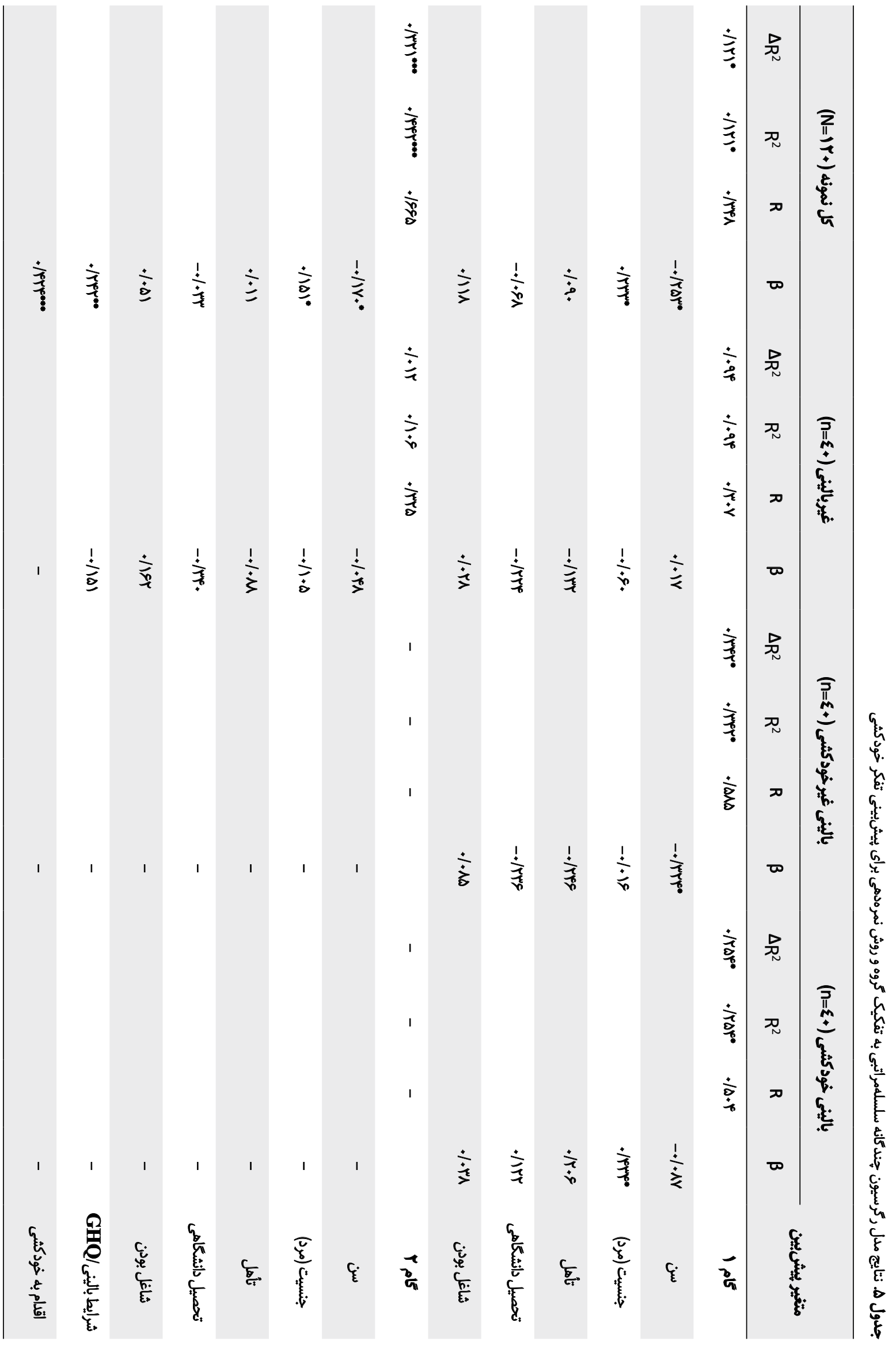




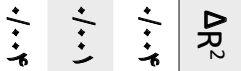

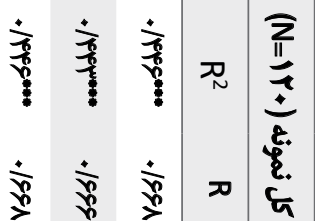

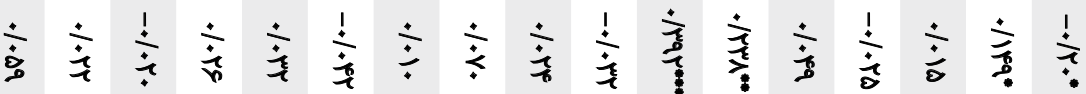

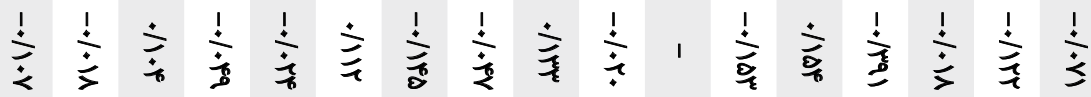

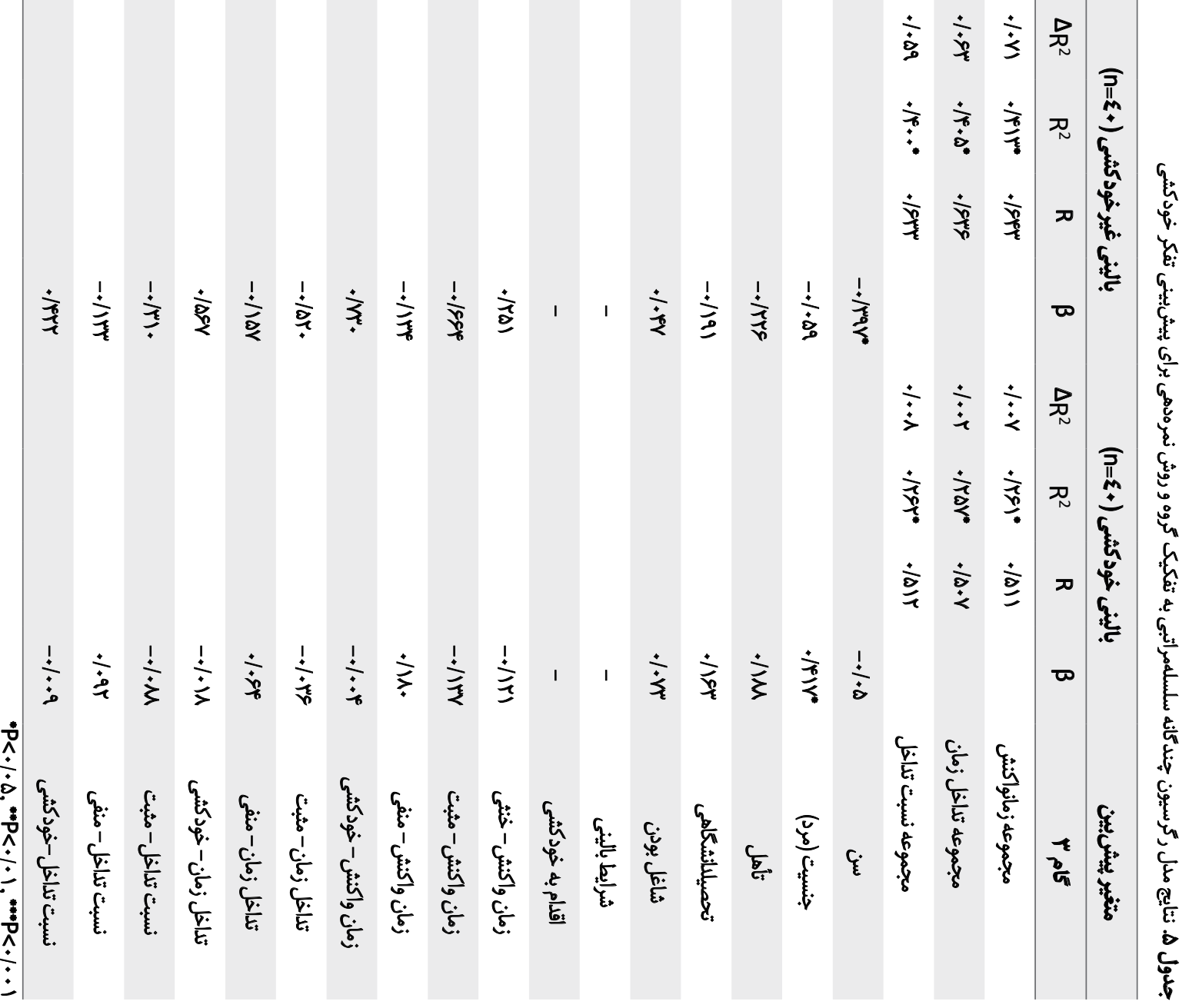



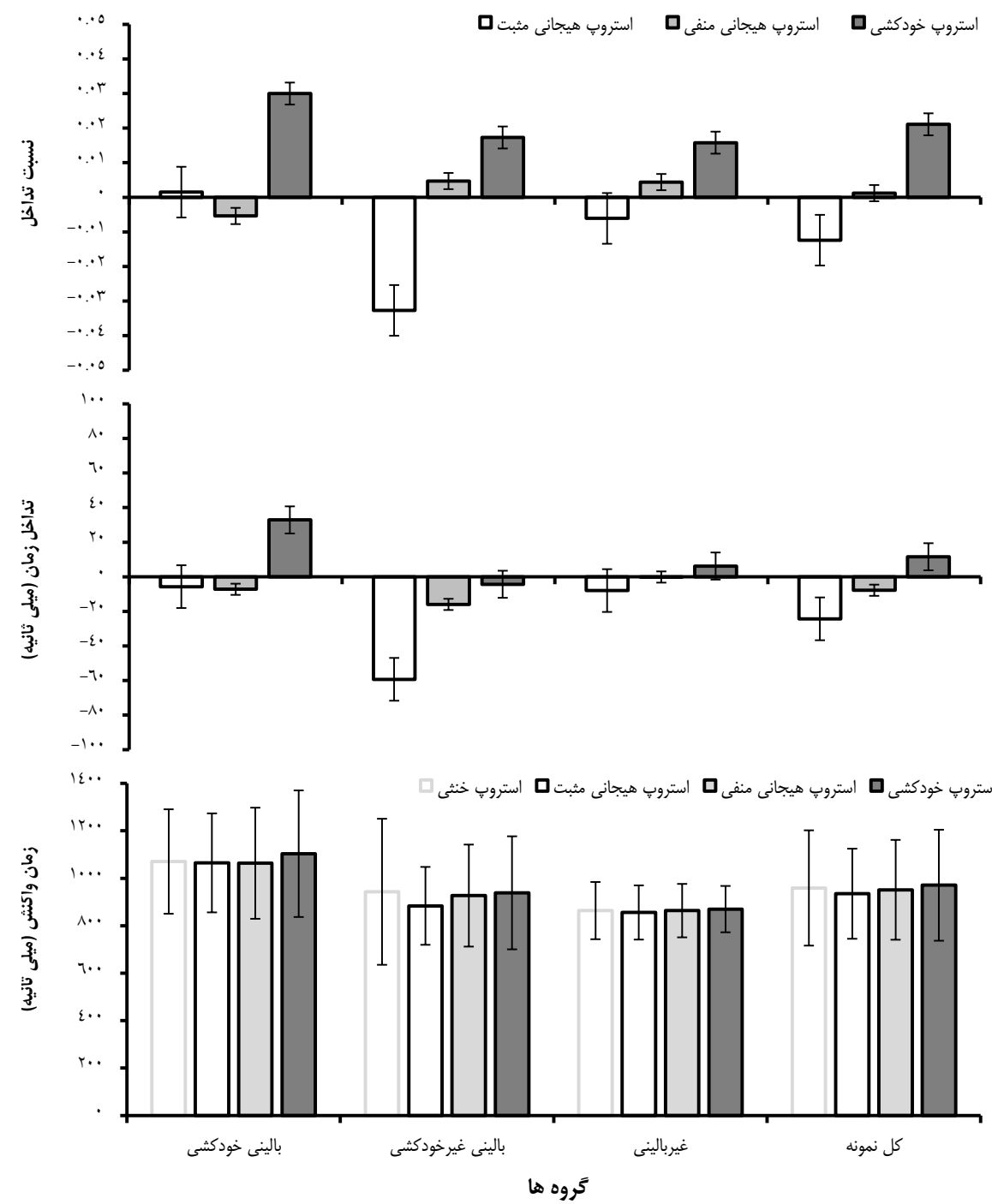

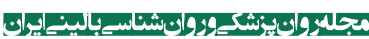

تصوير ا. ميانكين و ائحراف معيار زمان واكثش، تداخل زمان و نسبت تداخل كروهها در انواع استروب

بيشبينى تفكر خودكشى بر عهلده نداشتند.

همسو با اين نتايج، در برخى از مطالعات ارتباط معنادارى بين

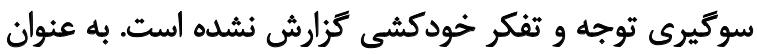

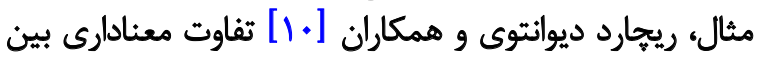

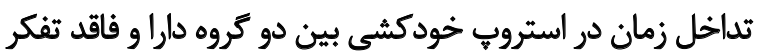

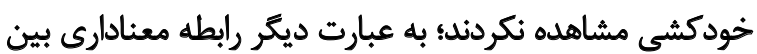

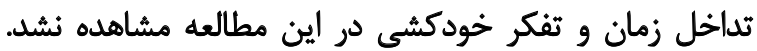

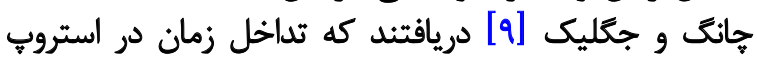

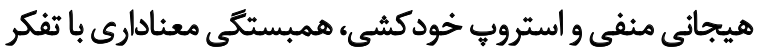

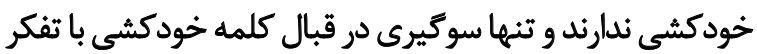

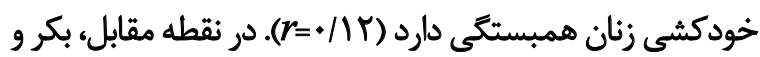

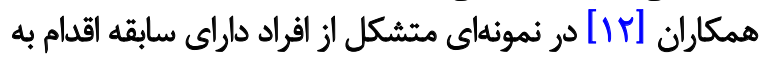
خودكشي و سالم، بين سوكيرى توجه در استروب خودكثي و
در زروه بالينى غيرخودكشى، اكرجه شاخصهاى مربوط

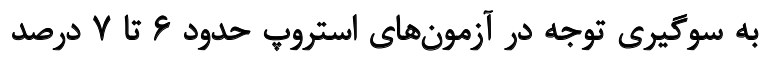

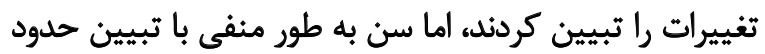

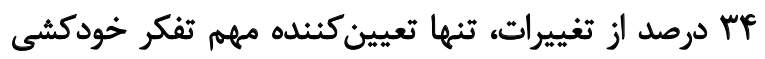

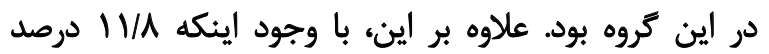

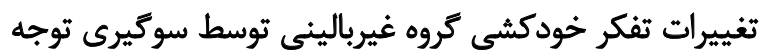

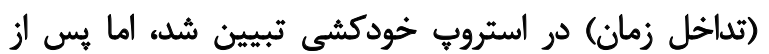

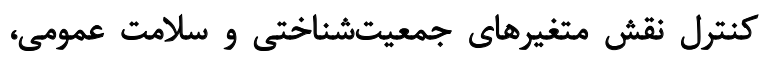

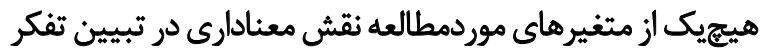

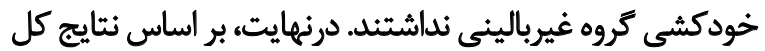

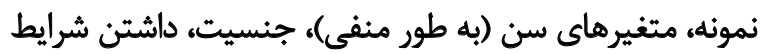

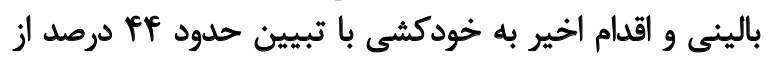

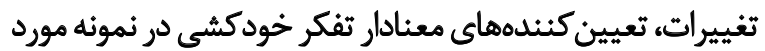

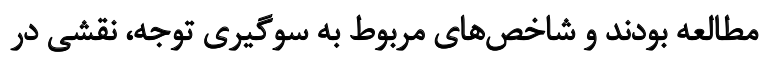


f. عوامل روانشناختى: بر اساس مدل شناختى رفتار

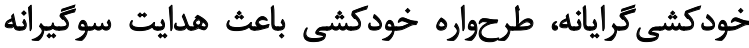

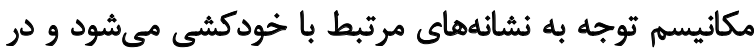

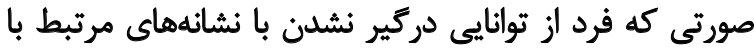

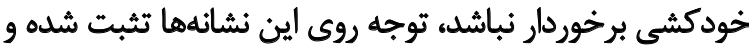

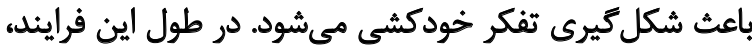

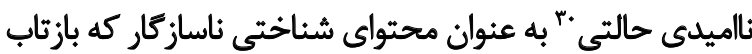

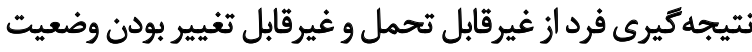

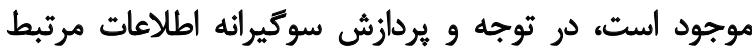

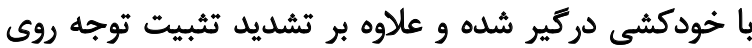

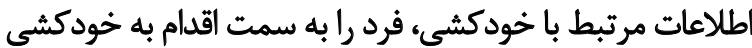

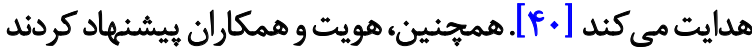

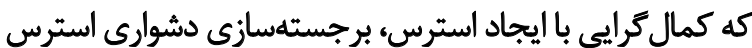

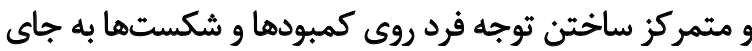

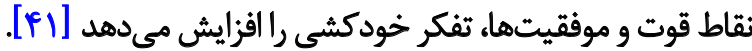

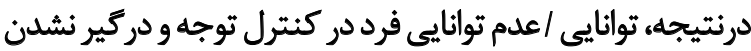

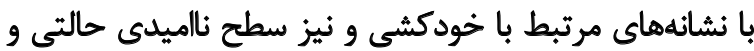

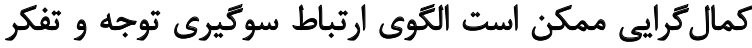
خودكشى راتحت تأثير قرار دهد.

يرؤش حاضر به صورت هدفمند در بيى ياسخ به اين سؤال

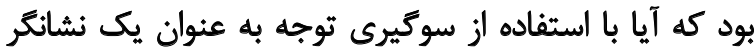

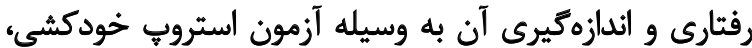

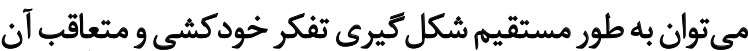

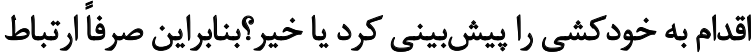

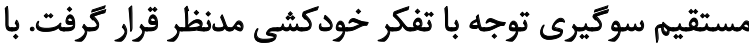

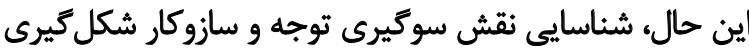

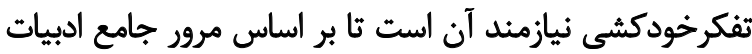

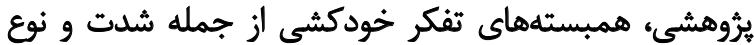

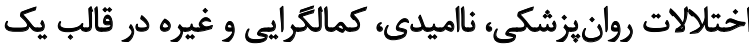

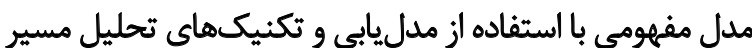
مورد مطالعه قرار كيرد.

اين درحالى است كه مطالعات كذشته به بررسى روابط دوسويه

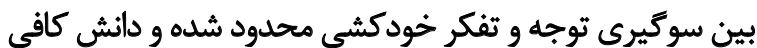

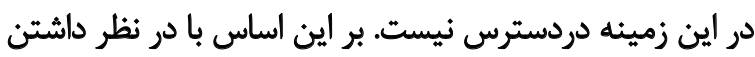

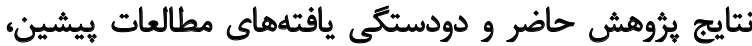

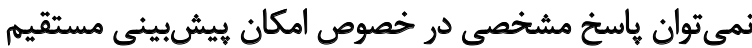

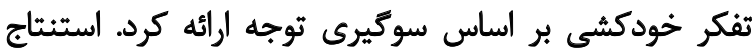

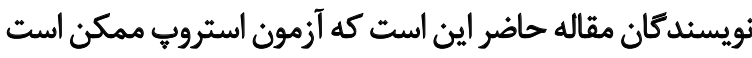
در تركيب باسنجش هاى ديكر مانيد ارزيابي توانايى كنترل توجينه امكان اين بيشيبنى را فراهم كندي

در يُوهش حاضر، سوكيرى توجه به محركهاى هيجانى مثبت

30. State Hopelessness

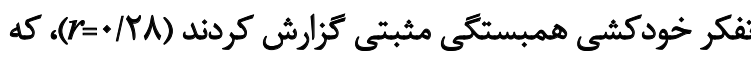

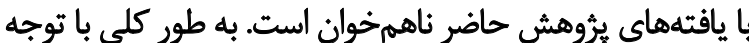

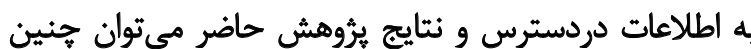

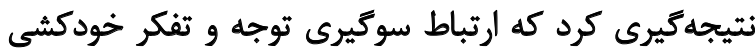

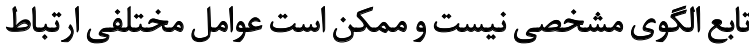

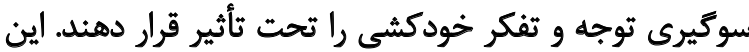

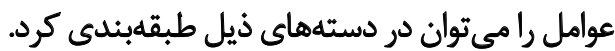
1. مقطع زمانى اندازهيرى سوكيرى توجه: تكليف استروب

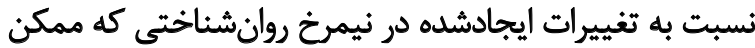

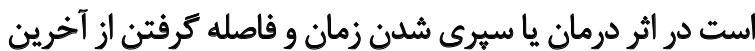

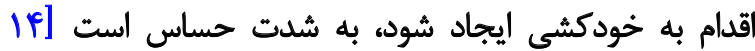

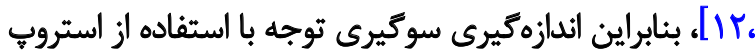

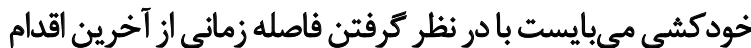
به خودكشى انجام شود.

r. توانايى يا نقص در ادراك بينايي: مهارتهاى بينايي و

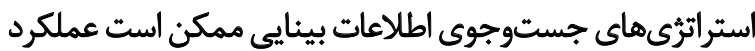

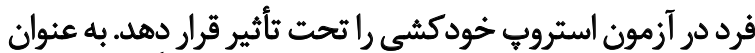

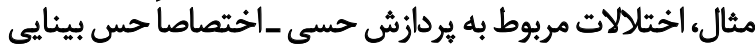

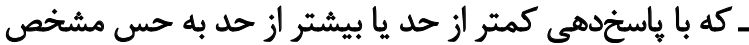

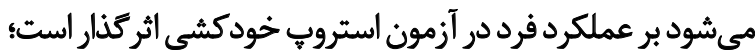

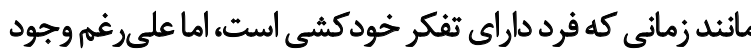

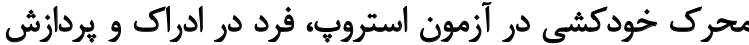

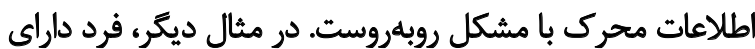

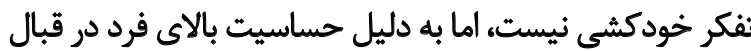

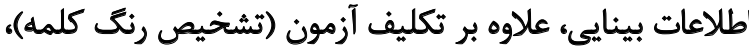

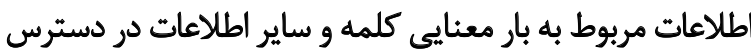

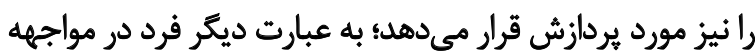

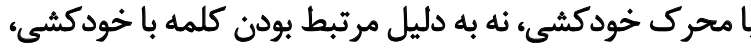

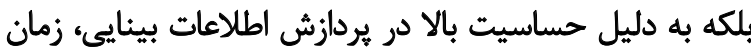
بيشترى رادر آزمون استروي صرف مي بلآدند.

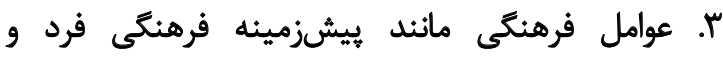

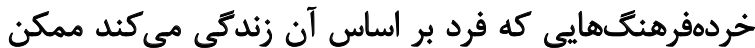

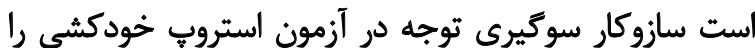

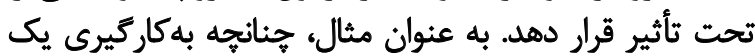

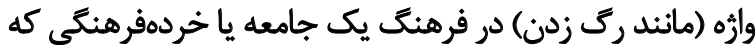

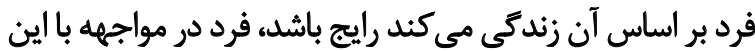

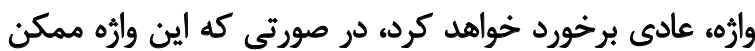

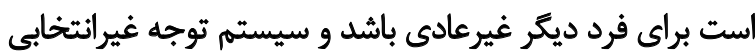

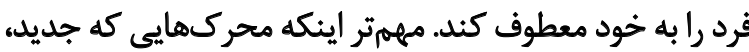

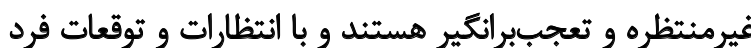

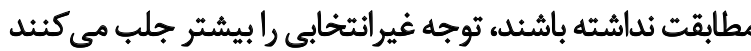

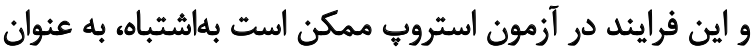

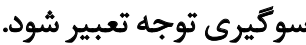


روانسنجى مطلوبتر و همجنين قدرت تحليل بالاترى را فراهم

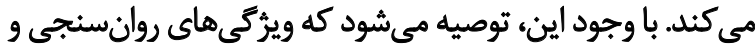

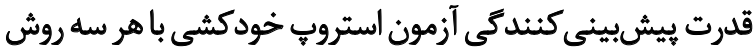

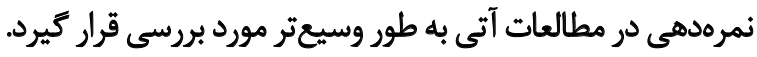
أكاهى و مد نظر قرار دادن محدوديتهايى كه هر بئروهش

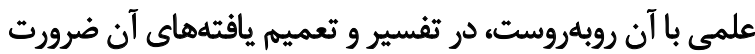

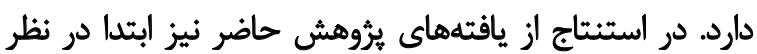

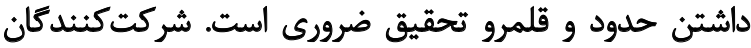

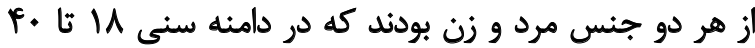

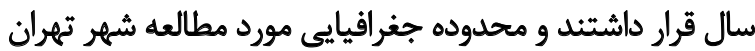

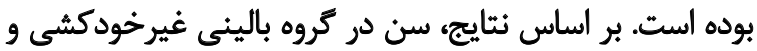

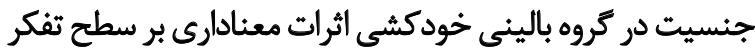

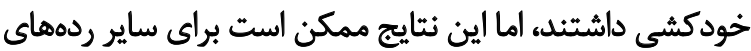

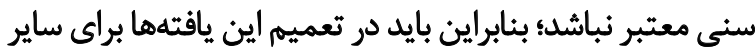
ردهاى سنى دقت لازم لحاظ شود.

از جمله محدوديتهايي كه در ئروهش حاضر خارج از كنترل

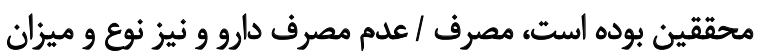

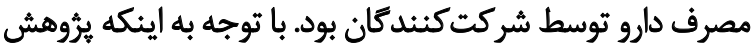

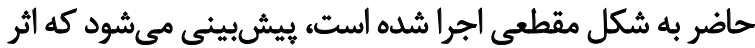

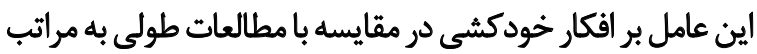

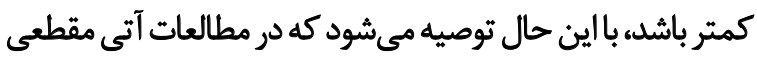

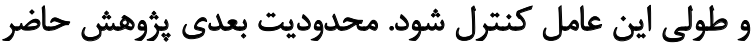

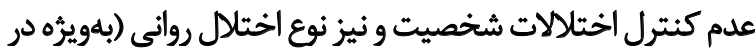

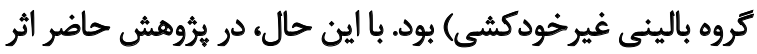

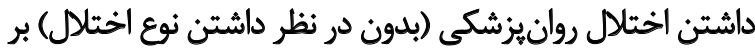

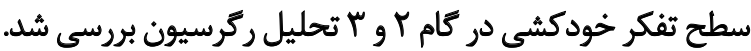

اختلال شخصيت و نوع اختلال روانى عواملى هستند كه در

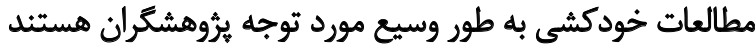

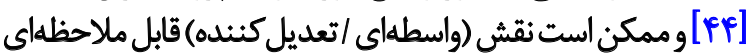
در ارتباط بين سوكيرى توجه و افكار خودكشى ايفا كنيند؛ بنابراين

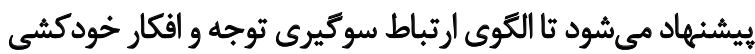

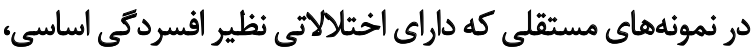

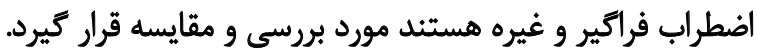

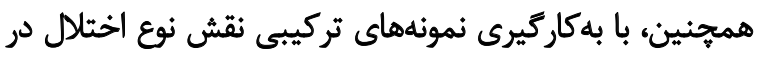
ارتباط بين سوكيرى توجه و تفكر خودكشى قابل مطالعه است.

نتيجهيرى

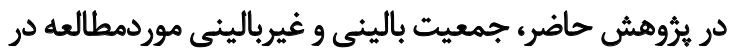

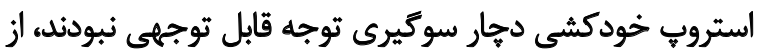

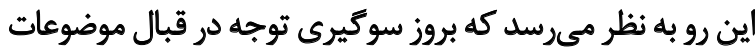

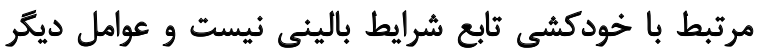

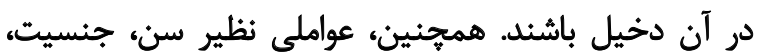
شرايط بالينى و سوابق رفتارهاى خودكشى برايانه كذُشته
و منفى نقش معنادارى در تفكر خودكشى برعهده نداشتند. با اين

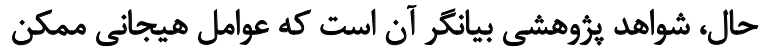

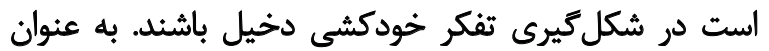

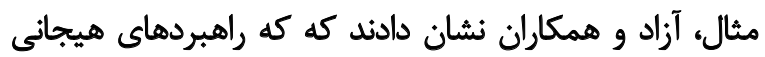

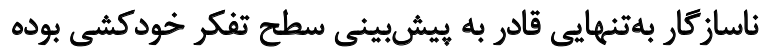

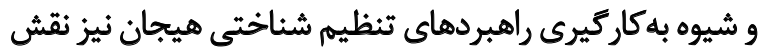

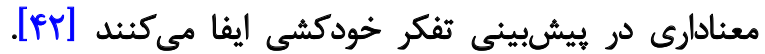

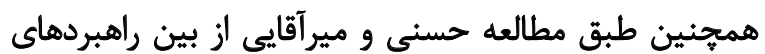

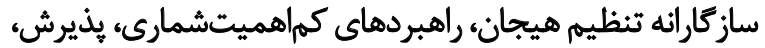

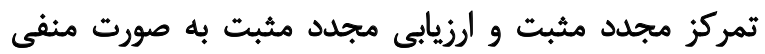

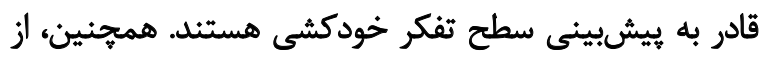

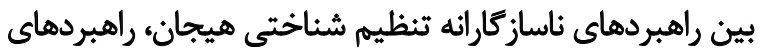

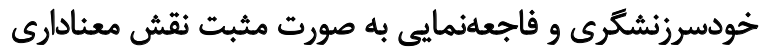

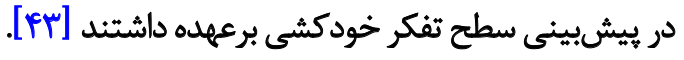

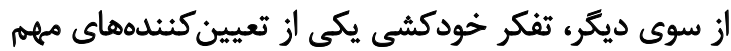

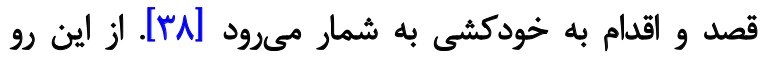

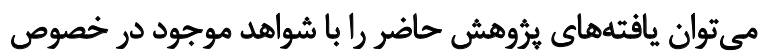

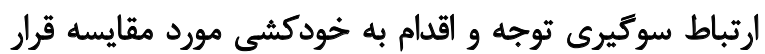

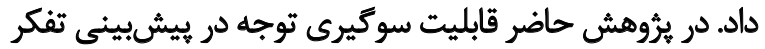

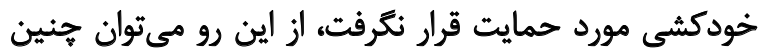

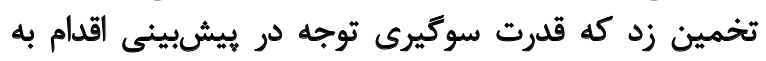

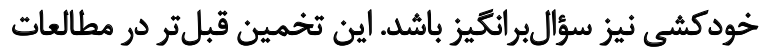

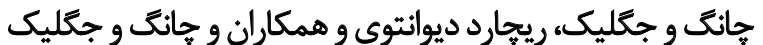

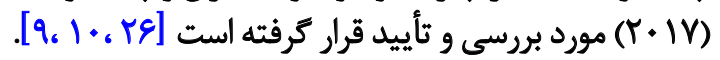

با اين حال در تعدادى از مطالعات بيشين از جمله ويليام و وران

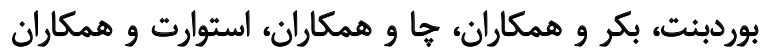

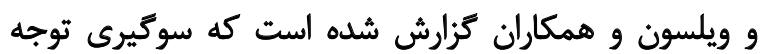

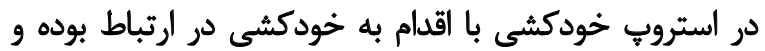

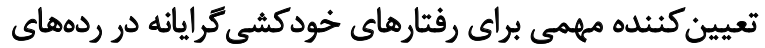

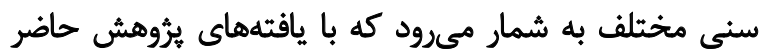

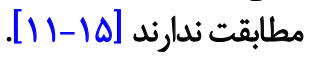

در فرايند يُووهش حاضر، آزمون استروب خودكشى براى

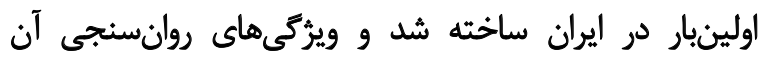

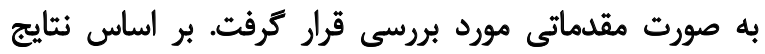

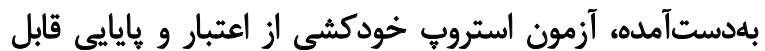

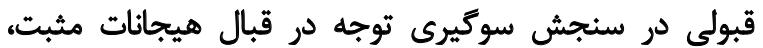

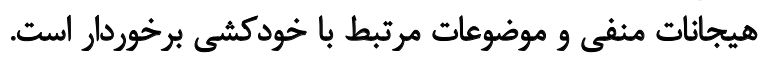

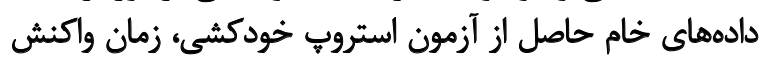

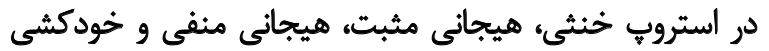

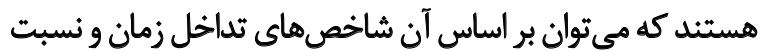

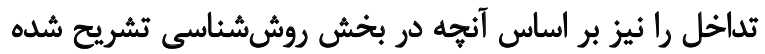

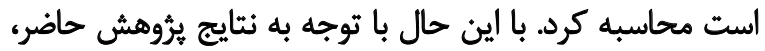

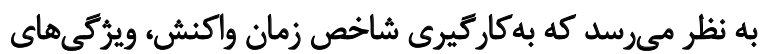


تعيين كنندههاي مهم تفكر خودكشى به شمار مىروند، اما ممكن

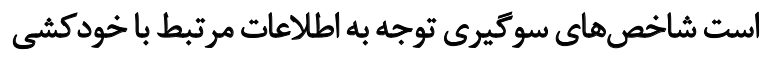
نقشى در ييشبينى تفكر خودكشى بر عهلده به نداشته باشند. ماحظات اخلاقي بيروى أز اصول اخلاق يُؤهش در اين يُوهش بيماران فرم رضايتنامه را تكميل و يثروهشگران تمامى ملاحظات اخلاقى رار رعايت كردند.

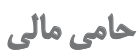
اين مقاله حامى مالى ندارد. مشار كت نويسند مثان تمام نويسندكان در آمادهازى اين مقاله مشاركت داشتهاند. تقارض مناقع بنابر اظهار نويسندكان اين مقاله تعارض منافع ندارد. 


\section{References}

[1] World Health Organization. Suicide data [Internet]. 2018 [Updated 2018]. Available from: www.who.int/mental_health/ prevention/suicide/suicideprevent/en

[2] Young Journalists Club. [The latest suicide statistics in Iran (Persian)] [Internet]. 2018 [Updated 2018 September 8]. Available from: www.yjc.ir/00Rwd6

[3] Hamedi A, Colborn VA, Bell M, Chalker SA, Jobes DA. Attentional bias and the Suicide Status Form: Behavioral perseveration of written responses. Behaviour Research and Therapy. 2019; 120:103403. [DOI:10.1016/j.brat.2019.04.011] [PMID]

[4] Cyders MA, Coskunpinar A. Measurement of constructs using self-report and behavioral lab tasks: Is there overlap in nomothetic span and construct representation for impulsivity? Clinical Psychology Review. 2011; 31(6):965-82. [DOI:10.1016/j. cpr.2011.06.001] [PMID]

[5] Goodman M. Affective startle and suicide risk. Paper presented at: The Suicide Prevention Research Interim Progress Report Meeting, Military Operational Medicine Research Program, May 2012; Ft. Detrick, MD, USA.

[6] Goodman M. High-risk suicidal behavior in veterans: Assessment and predictors and efficacy of dialectical behavior therapy. Paper presented at: The Suicide Prevention Research Interim Progress Report Meeting, Military Operational Medicine Research Program, May 2015; Ft. Detrick, MD, USA.

[7] Familoni BO, Ma L, Andrew Hutchinson J, Andrew Morgan C, Rasmusson A, O'Kane BL. SAFE for PTSD: Noncontact psychophysiological measure based on high-resolution thermal imaging to aid in PTSD diagnosis and assessment of treatment. Paper presented at: SPIE 8401, Independent Component Analyses, Compressive Sampling, Wavelets, Neural Net, Biosystems, and Nanoengineering. 10 May 2012; Baltimore, Maryland, United States. [DOI:10.1117/12.926464]

[8] Nock MK, Park JM, Finn CT, Deliberto TL, Dour HJ, Banaji MR. Measuring the suicidal mind: Implicit cognition predicts suicidal behavior. Psychological Science. 2010; 21(4):511-7. [DOI:10.1177/0956797610364762] [PMID] [PMCID]

[9] Chung Y, Jeglic EL. Use of the modified emotional Stroop task to detect suicidality in college population. Suicide \& Life-Threatening Behavior. 2016; 46(1):55-66. [DOI:10.1111/sltb.12174] [PMID]

[10] Richard-Devantoy S, Ding Y, Turecki G, Jollant F. Attentional bias toward suicide-relevant information in suicide attempters: A cross-sectional study and a meta-analysis. Journal of Affective Disorders. 2016; 196:101-8. [DOI:10.1016/j.jad.2016.02.046] [PMID]

[11] Wilson KM, Millner AJ, Auerbach RP, Glenn CR, Kearns JC, Kirtley OJ, et al. Investigating the psychometric properties of the suicide stroop task. Psychological Assessment. 2019; 31(8):105261. [DOI:10.1037/pas0000723] [PMID] [PMCID]

[12] Becker ES, Strohbach D, Rinck M. A specific attentional bias in suicide attempters. The Journal of Nervous \& Mental Disease. 1999; 187(12):730-5. [DOI:10.1097/00005053-19991200000004] [PMID]
[13] Williams JM, Broadbent K. Autobiographical memory in suicide attempters. Journal of Abnormal Psychology. 1986; 95(2):1449. [DOI:10.1037/0021-843X.95.2.144] [PMID]

[14] Cha CB, Najmi S, Park JM, Finn CT, Nock MK. Attentional bias toward suicide-related stimuli predicts suicidal behavior. ournal of Abnormal Psychology. 2010; 119(3):616-22. [DOI:10.1037/ a0019710] [PMID] [PMCID]

[15] Stewart JG, Glenn CR, Esposito EC, Cha CB, Nock MK, Auerbach RP. Cognitive control deficits differentiate adolescent suicide ideators from attempters. The Journal of Clinical Psychiatry. 2017; 78(6):e614-e21. [DOI:10.4088/JCP.16m10647] [PMID]

[16] Johnson A, Proctor RW. Attention: Theory and practice. Thousand Oaks, CA: SAGE Publications, Inc; 2004 [DOI:10.4135/9781483328768]

[17] Sohlberg MM, Mateer CA. Introduction to cognitive rehabilitation: Theory and practice. New York: Guilford Publications; 1989. https://books.google.com/books?id=d9mQgAACAAJ\&dq

[18] Notebaert L, Chrystal J, Clarke PJF, Holmes EA, MacLeod C. When we should worry more: Using cognitive bias modification to drive adaptive health behaviour. PLoS One. 2014; 9(1):e85092. [DOI:10.1371/journal.pone.0085092] [PMID] [PMCID]

[19] Williams JM, Mathews A, MacLeod C. The emotional Stroop task and psychopathology. Psychological Bulletin. 1996; 120(1):324. [DOI:10.1037/0033-2909.120.1.3] [PMID]

[20] Spanakis P, Jones A, Field M, Christiansen P. A stroop in the hand is worth two on the laptop: Superior reliability of a smartphone based alcohol stroop in the real world. Substance Use \& Misuse. 2019; 54(4):692-8. [DOI:10.1080/10826084.2018.15367 16] [PMID]

[21] Drobes DJ, Oliver JA, Correa JB, Evans DE. Attentional bias and smoking. In: Preedy VR, editor. Neuroscience of Nicotine: Mechanisms and Treatment. Cambridge, MA: Academic Press; 2019. pp. 145-50. [DOI:10.1016/B978-0-12-813035-3.00018-6]

[22] DeVito EE, Kiluk BD, Nich C, Mouratidis M, Carroll KM. Drug Stroop: Mechanisms of response to computerized cognitive behavioral therapy for cocaine dependence in a randomized clinical trial. Drug and Alcohol Dependence. 2018; 183:162-8. [DOI:10.1016/j.drugalcdep.2017.10.022] [PMID] [PMCID]

[23] van Timmeren T, Daams JG, van Holst RJ, Goudriaan AE. Compulsivity-related neurocognitive performance deficits in gambling disorder: A systematic review and meta-analysis. Neuroscience \& Biobehavioral Reviews. 2018; 84:204-17. [DOI:10.1016/j. neubiorev.2017.11.022] [PMID]

[24] Cisler JM, Bacon AK, Williams NL. Phenomenological characteristics of attentional biases towards threat: A critical review. Cognitive Therapy and Research. 2009; 33(2):221-34. [DOI:10.1007/ s10608-007-9161-y] [PMID] [PMCID]

[25] Wenzel A, Brown GK, Beck AT. Cognitive therapy for suicidal patients: Scientific and clinical applications. Washington, DC: American Psychological Association; 2009. [DOI:10.1037/11862000]

[26] Chung Y, Jeglic EL. Detecting suicide risk among college students: A test of the predictive validity of the modified emotional Stroop task. Suicide \& Life-Threatening Behavior. 2017; 47(4):398409. [DOI:10.1111/sltb.12287] [PMID] 
[27] Cha CB, Najmi S, Amir N, Matthews JD, Deming CA, Glenn JJ, et al. Testing the efficacy of attention bias modification for suicidal thoughts: Findings from two experiments. Archives of Suicide Research. 2017; 21(1):33-51. [DOI:10.1080/13811118.2016.1162 241] [PMID]

[28] Cha CB, O'Connor RC, Kirtley O, Cleare S, Wetherall K, Eschle $\mathrm{S}$, et al. Testing mood-activated psychological markers for suicidal ideation. Journal of Abnormal Psychology. 2018; 127(5):448-57. [DOI:10.1037/abn0000358] [PMID]

[29] Cohen J. Statistical power analysis for the behavioral sciences. $2^{\text {nd }}$ ed. Mahwah, NJ: Lawrence Erlbaum Associates; 1988. https:/ / books.google.com/books?id=cIJH0lR33bgC\&dq

[30] Goldberg DP, Hillier VF. A scaled version of the general health questionnaire. Psychological Medicine. 1979; 9(1):139-45. [DOI:10.1017/S0033291700021644] [PMID]

[31] Goldberg DP. The detection of psychiatric illness by questionnaire: A technique for the identification and assessment of non-psychotic psychiatric illness. London: Oxford University Press; 1972. https://books.google.com/ books?id=3schAQAAMAAJ\&dq

[32] Rezaei S, Salehi I, Yousefzadeh Chabok Sh, Moosavi H, Kazemnejad E. [Factor structure, clinical cut off point and psychometric properties of 28-items version for general health questionnaire in patients with traumatic brain injury (Persian)]. Journal of Guilan University of Medical Sciences. 2011; 20(78):56-70. http:/ / journal.gums.ac.ir/article-1-148-en.html

[33] Prady SL, Miles JNV, Pickett KE, Fairley L, Bloor K, Gilbody S, et al. The psychometric properties of the subscales of the GHQ-28 in a multi-ethnic maternal sample: Results from the Born in Bradford cohort. BMC Psychiatry. 2013; 13:55. [DOI:10.1186/1471244X-13-55] [PMID] [PMCID]

[34] Willmott SA, Boardman J, Henshaw C, Jones P. The predictive power and psychometric properties of the General Health Questionnaire (GHQ-28). Journal of Mental Health. 2008; 17(4):435-42. [DOI:10.1080/09638230701528485]

[35] Noorbala AA, Bagheri-Yazdi SA, Mohammad K. [The validation of general health questionnaire-28 as a psychiatric screening tool (Persian)]. Hakim Research Journal. 2009; 11(4):47-53. http:/ /hakim.hbi.ir/article-1-464-en.html

[36] Salehi Fadardi J, Ziaei SS. [Implicit cognitive processes and attention bias toward addictive behaviors: Introduction, development and application of addiction stroop test (Persian)]. Journal of Fundamentals of Mental Health. 2010; 12(45):358-89. [DOI:10.22038/JFMH.2010.886]

[37] Beck AT, Kovacs M, Weissman A. Assessment of suicidal intention: The scale for suicide ideation. Journal of Consulting and Clinical Psychology. 1979; 47(2):343-52. [DOI:10.1037/0022006X.47.2.343] [PMID]

[38] Beck AT. BSI, Beck scale for suicide ideation: Manual. San Antonio: Psychological Corporation; 1991. https:/ / books.google. com/books?id=bFFSHAAACAAJ\&dq

[39] Anisi J, Fathi Ashtiani A, Salimi SH, Ahmadi Nodeh Kh. [Validity and reliability of beck suicide scale ideation among soldiers (Persian)]. Journal of Military Medicine. 2005; 7(1):33-7. https:/ / www.sid.ir/fa/journal/ViewPaper.aspx?id=22790

[40] Wenzel A, Beck AT. A cognitive model of suicidal behavior: Theory and treatment. Applied and Preventive Psychology. 2008; 12(4):189-201. [DOI:10.1016/j.appsy.2008.05.001]
[41] Hewitt PL, Flett GL, Sherry SB, Caelian C. Trait perfectionism dimensions and suicidal behavior. In: Ellis TE, editor. Cognition and Suicide: Theory, Research, and Therapy. Washington, DC: American Psychological Association; 2006. pp. 215-35. [DOI:10.1037/11377-010]

[42] Azad M, Abdollahi MH, Hasani J. [Cognitive emotion regulation strategies in processing suicidal thoughts (Persian)]. Journal of Ilam University of Medical Sciences. 2014; 22(4):225-35. http:/ / sjimu.medilam.ac.ir/article-1-1289-en.html

[43] Hasani J, Miraghaie AM. [The relationship between strategies for cognitive regulation of emotions and suicidal ideation (Persian)]. Contemporary Psychology. 2012; 7(1):61-72. http:/ / bjcp. ir/article-1-26-en.html

[44] Ghoreishi SA, Mousavinasab N. [Systematic review of researches on suicide and suicide attempt in Iran (Persian)]. Iranian Journal of Psychiatry and Clinical Psychology. 2008; 14(2):115-21. http://ijpcp.iums.ac.ir/article-1-460-en.html 
This Page Intentionally Left Blank 